\title{
RULES AND REASONS IN THE THEORY OF PRECEDENT
}

\author{
John F. Horty* \\ University of Maryland
}

\section{INTRODUCTION}

The doctrine of precedent, as it has evolved within the common law, has at its heart a form of reasoning-broadly speaking, a logic-according to which the decisions of earlier courts in particular cases somehow generalize to constrain the decisions of later courts facing different cases, while still allowing these later courts a degree of freedom in responding to fresh circumstances. Although the techniques for arguing on the basis of precedent are taught early on in law schools, mastered with relative ease, and applied on a daily basis by legal practitioners, it has proved to be considerably more difficult to arrive at a theoretical understanding of the doctrine itself-a clear articulation of the underlying logic.

My purpose in this paper is to describe a new framework within which we can begin to address this problem. I concentrate on two of the most fundamental questions in the theory of precedent. First, how is it, exactly, that precedent cases constrain future decisions-what is the mechanism of constraint? And second, how is a balance then achieved between the constraints of precedent and the freedoms allowed to later courts for developing the law?

The view I present will be contrasted with three other views, or models, of precedential constraint appearing in the literature. The first is the rule model. A precedent case normally contains, not only a description of the facts of the case along with a decision on the basis of those facts, but also some particular rule through which that decision was reached. According to the rule model, it is this rule that carries the precedential constraint. Constraint by precedent just is constraint by rules; a precedent case constrains the decision of a later court when the rule contained in that precedent applies to the fact situation confronting the later court.

\footnotetext{
* This paper owes much to conversations with Kevin Ashley, Henry Prakken, and Mark Schroeder and written comments from Bruce Chapman. I am particularly indebted to Robin Kar for extensive corrections and suggestions, many of which have been incorporated directly into the text.
} 
A particularly strict version of the rule model is advanced by Larry Alexander and developed by Alexander and Emily Sherwin. ${ }^{1}$ According to this strict rule model, the constraints carried by precedent rules are very nearly absolute, with the result that the freedoms given to later courts for developing the law are extremely limited. When a precedent rule applies to a later fact situation, a court confronting that fact situation has, at most, two choices: the court must either follow the precedent rule, or, if that court has the authority to do so, it can overrule the precedent. There is, however, nothing in the general idea that precedential constraint is carried through rules that forces this very strict interpretation. A number of writers, while still adhering to this general idea, argue for a more flexible version of the rule model, according to which later courts have the power to develop the law by modifying without overruling the rules contained in precedent cases. The process through which these earlier rules might be modified, or distinguished, as well as the constraints on this process of distinguishing a precedent rule, are described with particular care by A.W.B. Simpson and Joseph Raz. ${ }^{2}$

The idea that precedential constraint is carried through rules surely reflects the popular conception of the matter, and at least the more flexible version of the rule model, according to which precedent rules can be distinguished, is perhaps the received view among legal theorists. Still, two further views deserve our attention. The second model of precedential constraint to be considered here is the result model. ${ }^{3}$ According to this model, what matters about a precedent case is not the rule it contains but first, the result of the case, and second, the strength of that case for its result. Precedential constraint is then thought to be a simple matter of a fortiori reasoning: a later court is constrained to follow the ruling of a precedent case when the facts confronting the later court are at least as strong for the winning side of the precedent case as were the facts of the precedent case itself. The result model of precedent depends, of course, on some definite way of measuring the strength of a case for one side or another. The idea that there might be such a measure is criticized by Alexander as unattractive and perhaps incoherent, but I elsewhere defend the idea as coherent at least and as one that holds some attractions even if it does not tell the whole story. ${ }^{4}$

1. See Larry Alexander, Constrained by Precedent, 63 S. CAL. L. Rev. 1-64 (1989), many of the arguments from which are summarized in Larry Alexander, Precedent, in A COMPANION TO Philosophy of LaW ANd Legal TheOry (D. Patterson ed., 1996), at 503-513; see also LARRY Alexander \& Emily Sherwin, The Rule of Rules: Morality, Rules, and the Dilemmas of LaW (2001). The term "rule model" is itself due to Alexander, who applies it only to what I describe here as the strict rule model, which reflects his own preferred view; I use the term more broadly to apply to any model in which precedential constraint is thought to be carried by rules.

2. See A.W.B. Simpson, The Ratio Decidendi of a Case and the Doctrine of Binding Precedent, in Oxford Essays in Jurisprudence 148-175 (A.G. Guest ed., 1961); and JosepH Raz, The Authority OF LAW (1979), ch. 10.

3. The term is again from Alexander, Constrained, supra note 1.

4. See John Horty, The Result Model of Precedent, 10 Legal Theory 19-31 (2004). 
The third view of precedential constraint to be considered here, recently introduced by Grant Lamond, may be termed the reason model. ${ }^{5}$ According to Lamond, what is most important about an earlier court's decision in a precedent case is, not the rule it contains nor even the strength of the precedent case for one side or another, but instead, the earlier court's assessment of the balance of reasons presented by the facts of that case. The requirement of precedential constraint can then be defined as follows: unless it wishes to overrule the precedent, a later court is constrained to reach a decision that is consistent with the earlier court's assessment of the balance of reasons. My own view, as we will see, makes crucial use of this idea and contributes a precise account of what it means for a later decision to be consistent with a previous assessment of the balance of reasons.

A central advantage of the account to be presented here is that it shows how these three theoretical models of precedent-rule, result, and reasoncan be, in a precise sense, unified; it helps us see what is correct in each of these views and how they are related. The unification between the rule model and the reason model is achieved by interpreting the rules contained in precedent cases, not as strict rules, but as default or defeasible rules, while reasons then serve as the premises of rules. As we see below, this analysis of reasons as the premises of default rules is not at all unnatural, nor is it ad hoc, introduced only to establish a connection between two theoretical models of legal precedent; indeed, it is something that I defend elsewhere on independent grounds. ${ }^{6}$ The unification between the rule model and the result model is achieved even more simply by showing that the result model is simply a special case of the rule model developed here, in which precedent rules are either assumed or required to exhibit a certain form.

The key innovation of the present account is that it makes explicit what is generally only implicit in case law: a priority ordering representing the strength of the reasons underlying judicial decisions. Like the set of rules contained in precedent cases, the priority ordering on reasons is itself taken to be a part of the law, although, like the precedent rules themselves, the priority ordering is derived from the decisions reached in precedent cases, not defined independently. Once this priority ordering has been made explicit, the notion of consistency with past decisions, and so precedential constraint, can then be defined, and new light shed on other aspects of precedential reasoning as well.

The paper is organized as follows. The next section lays out basic ideas and notation. The third section defines our central ordering relation on reasons, and also relates reasons to rules; using this ordering, the fourth section then presents the core theory of precedential constraint and explores some of the issues surrounding a transitive extension of the core theory. The fifth section focuses on case base dynamics — the effects of following or distinguishing a

5. See Grant Lamond, Do Precedents Create Rules?, 11 Legal TheORY 1-26 (2005).

6. See John Horty, Reasons as Default, 7 Philosophers' Imprint (2007). 
precedent. The sixth section compares the account developed here with a version of the result model of precedent, and the seventh concludes with a discussion of some open issues. The paper relies on various abstract cases and fact situations to illustrate the concepts introduced here and includes a number of observations concerning properties of these concepts; the abstract cases and fact situations are collected together in a first appendix while the observations are verified in a second.

\section{FACTORS, RULES, AND CASES}

I follow the work of Kevin Ashley and his colleagues in supposing that the situation presented to the court in a legal case can usefully be represented as a set of factors, where a factor stands for a legally significant fact or pattern of facts. ${ }^{7}$ Cases in different areas of the law will be characterized by different sets of factors, of course. In the domain of trade-secrets law, for example, where the factor-based analysis has been developed most extensively, a case will typically concern the issue of whether the defendant has gained an unfair competitive advantage over the plaintiff through the misappropriation of a trade secret; and here the factors involved might turn on, say, questions concerning whether the plaintiff took measures to protect the trade secret, whether a confidential relationship existed between the plaintiff and the defendant, whether the information acquired was reverse-engineerable or in some other way publicly available, and the extent to which this information did in fact lead to a real competitive advantage for the defendant. ${ }^{8}$

Many factors can naturally be taken to have polarities, favoring one side or another. In the domain of trade-secrets law, again, the presence of security measures favors the plaintiff, since it strengthens the claim that the information secured was a valuable trade secret; reverse-engineerability favors the defendant, since it suggests that the product information might have been acquired through proper means. The present paper is based on the simplifying assumption, not just that many or even most factors have

7. See Kevin Ashley, Toward a Computational Theory of Arguing with Precedents: Accommodating Multiple Interpretations of Cases, in ProceEdings of the SECOND INTERnATIONAL Conference ON Artificial InTELligence AND LAW (ICAIL-89), 93-110 (1989); and Kevin Ashley, Modeling Legal Argument: Reasoning With CASES And Hypotheticals (1990), for an introduction to the model; see also Edwina Rissland, Artificial Intelligence and Law: Stepping Stones to a Model of Legal Reasoning, 99 YALE L.J. 1957-1981 (1990), for an overview of research in artificial intelligence and law that places this work in a broader context.

8. Vincent Aleven, "Teaching Case-Based Argumentation through a Model and Examples," Ph.D. thesis, Intelligent Systems Program, University of Pittsburgh, 1997, analyzes 147 cases from trade-secrets law in terms of a factor hierarchy that includes five high-level issues, eleven intermediate-level concerns, and twenty six base-level factors. The resulting knowledge base is used in an intelligent tutoring system for teaching elementary skills in legal argumentation, which has achieved results comparable to traditional methods of instruction in controlled studies; see Vincent Aleven \& Kevin Ashley, Evaluating a Learning Environment for Case-Based Argumentation Skills, in Proceedings of the Sixth International Conference on Artificial INTELLIGENCE AND LAW (ICAIL-97) 170-179 (1997). 
polarities but that all factors are like this, favoring one particular side. And I suppose, as an additional simplification, that the reasoning under consideration involves only a single step proceeding immediately from the factors present in a case to a decision-in favor of the plaintiff or the defendantrather than moving through a series of intermediate legal concepts. Both of these assumptions would have to be relaxed in a more complete theory.

Of course, it must be noted also that the mere ability to understand a case in terms of the factors it presents itself requires a significant degree of legal expertise, which is presupposed here. Our theory thus starts with cases to which we must imagine that this expertise has already been applied, so that they can be represented directly in terms of the factors involved; we are concerned here only with the subsequent reasoning.

Formally, then, let us begin by postulating a set, $F$, of legal factors. A fact situation $X$, of the sort presented in a legal case, can then be defined as some particular subset of these factors: $X \subseteq F$. We let $F^{\pi}=\left\{f_{1}^{\pi}, \ldots, f_{n}^{\pi}\right\}$ represent the set of factors favoring the plaintiff and $F^{\delta}=\left\{f_{1}^{\delta}, \ldots, f_{m}^{\delta}\right\}$ the set of factors favoring the defendant. Given our assumption that each factor favors one side or the other, we can suppose that the entire set of legal factors is exhausted by those favoring the plaintiff together with those favoring the defendant: $F=F^{\pi} \cup F^{\delta}$.

A precedent case is represented as a fact situation together with an outcome as well as a rule through which that outcome is reached. Such a case, then, can be defined as a triple of the form $c=\langle X, r, s\rangle$, where $X$ is a fact situation containing the legal factors present in the case, $r$ is the rule of the case, and $s$ is its outcome. ${ }^{9}$ We define three functions-Facts, Rule, and Outcometo map cases into their component parts, so that in the case $c$ above, for example, we would have Facts $(c)=X$, Rule $(c)=r$, and Outcome $(c)=s$.

Given our assumption that reasoning proceeds in a single step, we can suppose that the outcomes of a case is always either a decision in favor of the plaintiff or a decision in favor of the defendant, with these two outcomes represented as $\pi$ or $\delta$ respectively; and where $s$ is a particular outcome, a decision for some side, we suppose that $\bar{s}$ represents a decision for the opposite side, so that $\bar{\pi}=\delta$ and $\bar{\delta}=\pi$. Where $X$ is a fact situation, we let $X^{s}$ represent the factors from $X$ that support the side $s$; that is, $X^{\pi}=X \cap F^{\pi}$ and $X^{\delta}=X \cap F^{\delta}$.

The rule $r$ contained in a precedent case has the form $Y \rightarrow s$, where $Y$ is some set of factors supporting $s$ as an outcome. We define two functionsPremise and Conclusion-picking out the premise and the conclusion of a

9. For the purpose of this paper, I simplify by assuming that the rule underlying a court's decision is plain, ignoring the extensive literature on methods for determining the rule, or ratio decidendi, of a case. I also assume that a case always contains a single rule, ignoring situations in which a judge might offer several rules for a decision or in which a court reaches a decision by majority, with different judges offering different rules, or in which a judge might simply render a decision in a case without setting out any general rule at all; see, however, the sixth section of this paper, in which I suggest one way of interpreting cases in which decisions are not accompanied by rules. 
rule, so that, in the case of this particular rule $r$, for example, we would have Premise $(r)=Y$ and Conclusion $(r)=s$. A precedent rule of this sort, once again, is to be interpreted as a defeasible rule, telling us that its premise entails its conclusion not as a matter of necessity but only by default. What the rule $Y \rightarrow s$ means, then, is that, if some fact situation contains all the factors from $Y$, then, as a default, the court ought to reach a decision in this situation in favor of the side $s$-or perhaps more intuitively, that the factors from $Y$, taken together, provide the court with a reason for deciding in favor of the side $s$.

This connection between precedent rules and reasons-a guiding theme of the paper-can be illustrated by examining a different sort of normative rule, an ethical generalization, such as "If you make a promise, you ought to keep it." Consider an instance of this generalization, such as "If I promise to have lunch with Alex, I ought to do so," and suppose that I have in fact promised to have lunch with Alex, so that the rule is applicable. What, then, is the force of this rule? It cannot mean that I ought to have lunch with Alex no matter what. Surely other, more important obligations might legitimately interfere; I might be called upon to save a life, for example. Instead, it is natural to interpret the rule as telling us that my promise, the premise of the rule, provides me with a reason for having lunch with Alex-presumably a very strong reason or a reason with special moral force, since it is based on a promise, but still a reason that might be defeated by stronger reasons, or perhaps excluded from consideration entirely. ${ }^{10}$

The idea behind the current account is that precedent rules work in exactly the same way, identifying legal reasons that support particular decisions. What the rule $Y \rightarrow s$ tells us, then, is that the factor set $Y$ provides the court with a legal reason for deciding in favor of the side $s$. Just as in the case of ethical generalizations, however, the reason provided by this precedent rule may be defeated-or trumped, as we will say—by a stronger legal reason favoring the opposite side, in a way that is explained below.

Let us return, now, to the concept of a precedent case $c=\langle X, r, s\rangle$ containing a fact situation $X$ along with a rule $r$ leading to the outcome $s$. In order for this concept to make sense, we impose three coherence constraints. First, the rule contained in the case must be applicable to the facts of the case, in the sense that the fact situation contains the factors required by the premise of the rule: $\operatorname{Premise}(r) \subseteq X$. Second, each of the factors contained in the premise of the precedent rule must actually support its conclusion, not the opposite side: where Conclusion $(r)=s$, then, we require Premise $(r) \subseteq F^{s}$. And third, the conclusion of the precedent rule must match the outcome of the case: Conclusion $(r)=$ Outcome $(c)$.

10. This general picture is described in much more detail in Horty supra note 6 , available at http:/ / www.philosophersimprint.org/007003/, where I appeal to techniques from nonmonotonic logic to develop a detailed theory as reasons as the premises of default rules; the theory allows us to understand both how reasons can be defeated by stronger reasons and how they can be excluded from consideration in the way suggested in JOSEPH RAZ, PRACTICAL REASONING AND NoRMs, 2d ed. (2002). 
These various concepts and constraints can be illustrated through the concrete case $c_{1}=\left\langle X_{1}, r_{1}, s_{1}\right\rangle$, containing the fact situation $X_{1}=$ $\left\{f_{1}^{\pi}, f_{2}^{\pi}, f_{3}^{\pi}, f_{1}^{\delta}, f_{2}^{\delta}, f_{3}^{\delta}, f_{4}^{\delta}\right\}$, with three factors favoring the plaintiff and four favoring the defendant, where $r_{1}$ is the rule $\left\{f_{1}^{\pi}, f_{2}^{\pi}\right\} \rightarrow \pi$, and where the outcome $s_{1}$ is $\pi$, a decision for the plaintiff. Evidently, the case satisfies our three coherence constraints. The precedent rule is applicable to the fact situation in the sense that Premise $\left(r_{1}\right) \subseteq X_{1}$. The various factors contained in the premise of this rule all support its conclusion, a decision for the plaintiff, in the sense that Premise $\left(r_{1}\right) \subseteq F^{\pi}$. And the conclusion of the precedent rule matches the outcome of the case, both favoring the plaintiff: Conclusion $\left(r_{1}\right)=$ Outcome $\left(c_{1}\right)$. This particular precedent, then, represents a case in which the court decides for the plaintiff by applying or introducing a rule according to which the presence of the factors $f_{1}^{\pi}$ and $f_{2}^{\pi}$ lead, by default, to a decision for the plaintiff.

\section{ORDERED REASONS AND BINDING RULES}

With this notion of a precedent case in hand, we can now define a case base as a set $\Gamma$ of precedent cases. It is a case base of this sort that will be taken to represent the common law in some area and to constrain the decisions of future courts. ${ }^{11}$ But according to the present theory, these constraints depend more immediately on two additional concepts, both of which can be defined in terms of the case base.

The first is simply the set of rules derived from a case base, which is definable as the set containing any rule belonging to any case from that case base. The concept can be introduced formally by extending the function Rule, which extracts the rule from a single case, so that it applies also to an entire set of cases, yielding as a result the set of rules contained in those cases:

Definition 1 (Rules derived from a case base). Let $\Gamma$ be a case base. Then the set $\operatorname{Rule}(\Gamma)$ of rules derived from $\Gamma$ is defined by taking $\operatorname{Rule}(\Gamma)=$ $\{\operatorname{Rule}(c): c \in \Gamma\}$.

To illustrate, suppose the case base $\Gamma$ contains the case $c_{1}$, considered above. Then the set Rule $(\Gamma)$ of rules derived from this case base will contain the particular rule $r_{1}$, since this rule is the value of $R u l e\left(c_{1}\right)$, and $c_{1}$ belongs to $\Gamma$.

It is, of course, customary to suppose that the rules derived from a case base play an important role in precedential constraint; some writers argue that these precedent rules play the entire role. The second concept we introduce - a preference relation on reasons-is much less common as a focus of attention.

11. Although I focus in this paper on which might be called "pure" common law, I believe the model would also apply to cases in which precedential reasoning is used to interpret statutory or constitutional language. 
In order to motivate this concept, it will be useful to consider our previous example, the case $c_{1}$, in more detail. The key idea underlying precedential constraint is that later courts must respect the decisions of earlier courts. So what information is actually carried by the earlier court's decision in the case of $c_{1}$ ? What is the earlier court telling us with this decision? Well, two things at least. First, by appealing to the rule $r_{1}$, the court is telling us that the premise of this rule-that is, Premise $\left(r_{1}\right)$, or $\left\{f_{1}^{\pi}, f_{2}^{\pi}\right\}$-is a sufficient reason for reaching a decision in favor of the plaintiff. But second, with its decision for the plaintiff, the court is also telling us that this reason is preferred to whatever other reasons the case might present that favor the defendant.

To make this point precisely, let us now define a legal reason as a set of factors uniformly favoring one side or the other. For example, $\left\{f_{1}^{\pi}, f_{2}^{\pi}\right\}$ is a reason favoring the side $\pi$, a decision for the plaintiff, whereas $\left\{f_{1}^{\delta}, f_{2}^{\delta}\right\}$ is a reason favoring the side $\delta$, a decision for the defendant; but according to this definition $\left\{f_{1}^{\pi}, f_{1}^{\delta}\right\}$ is not a reason at all, since the factors contained in this set do not uniformly favor either side. We can say that a fact situation presents a reason if all the factors from that reason are contained in that fact situation and that a case presents a reason if its fact situation does so. Finally, if $X$ and $Y$ are reasons favoring the same side, we can say that $Y$ is at least as strong as $X$ whenever $Y$ contains all the factors contained by $X$-whenever, that is, $X \subseteq Y$.

Returning to our example, the case $c_{1}$, as we have seen, contains the set $X_{1}=\left\{f_{1}^{\pi}, f_{2}^{\pi}, f_{3}^{\pi}, f_{1}^{\delta}, f_{2}^{\delta}, f_{3}^{\delta}, f_{4}^{\delta}\right\}$ as its fact situation, and so the strongest reason presented by this case for the defendant is the subset $X_{1}^{\delta}=\left\{f_{1}^{\delta}, f_{2}^{\delta}, f_{3}^{\delta}, f_{4}^{\delta}\right\}$, containing all those factors from the original fact situation that favor the defendant. Since the earlier court has decided for the plaintiff on the grounds of the reason provided by Premise $\left(r_{1}\right)$ even in the face of the reason provided by $X_{1}^{\delta}$ for the defendant, it seems to follow as a consequence of the court's decision that the reason Premise $\left(r_{1}\right)$ for the plaintiff is preferred to the reason $X_{1}^{\delta}$ for the defendant-that is, that the reason $\left\{f_{1}^{\pi}, f_{2}^{\pi}\right\}$ is preferred to the reason $\left\{f_{1}^{\delta}, f_{2}^{\delta}, f_{3}^{\delta}, f_{4}^{\delta}\right\}$. If we introduce the symbol $<_{c_{1}}$ to represent the preference relation on reasons that is derived from the particular case $c_{1}$, then this consequence of the court's decision can be put more formally as the claim that $\left\{f_{1}^{\delta}, f_{2}^{\delta}, f_{3}^{\delta}, f_{4}^{\delta}\right\}<_{c_{1}}\left\{f_{1}^{\pi}, f_{2}^{\pi}\right\}$, or equivalently, that $X_{1}^{\delta}<_{c_{1}}$ Premise $\left(r_{1}\right)$.

As far as the preference ordering goes, then, the earlier court is telling us at least that $X_{1}^{\delta}<_{c_{1}}$ Premise $\left(r_{1}\right)$, but is it telling us anything else? Perhaps not explicitly, but implicitly, yes. For if the reason Premise $\left(r_{1}\right)$ for the plaintiff is preferred to the reason $X_{1}^{\delta}$ for the defendant, then surely any reason for the plaintiff that is at least as strong as Premise $\left(r_{1}\right)$ must likewise be preferred to $X_{1}^{\delta}$, and just as surely Premise $\left(r_{1}\right)$ must be preferred to any reason for the defendant that is at least as weak as $X_{1}^{\delta}$. As we have seen, a reason $Z$ for the plaintiff is at least as strong as $\operatorname{Premise}\left(r_{1}\right)$ if it contains all the factors contained by $\operatorname{Premise}\left(r_{1}\right)$-that is, if Premise $\left(r_{1}\right) \subseteq Z$. And it is 
natural to conclude likewise that a reason $W$ for the defendant is at least as weak as $X_{1}^{\delta}$ if it contains no more factors than $X_{1}^{\delta}$ itself-that is, if $W \subseteq X_{1}^{\delta}$. It therefore follows from the earlier court's decision in $c_{1}$, not only that $X_{1}^{\delta}<_{c_{1}} \operatorname{Premise}\left(r_{1}\right)$, but that $W<_{c_{1}} Z$ whenever $W$ is at least as weak a reason for the defendant as $X_{1}^{\delta}$ and $Z$ is at least as strong a reason for the plaintiff as Premise $\left(r_{1}\right)$-whenever, that is, $W \subseteq X_{1}^{\delta}$ and Premise $\left(r_{1}\right) \subseteq Z$. To illustrate: from the court's explicit decision that $\left\{f_{1}^{\delta}, f_{2}^{\delta}, f_{3}^{\delta}, f_{4}^{\delta}\right\}<_{c_{1}}\left\{f_{1}^{\pi}, f_{2}^{\pi}\right\}$, we can also conclude that $\left\{f_{3}^{\delta}, f_{4}^{\delta}\right\}<_{c_{1}}\left\{f_{1}^{\pi}, f_{2}^{\pi}, f_{5}^{\pi}\right\}$, for example.

This line of argument leads to the following definition of the preference relation among reasons that can be derived from a single case:

Definition 2 (Preference relation derived from a case). Let $c=\langle X, r, s\rangle$ be a case, and suppose $W$ and $Z$ are reasons. Then the relation $<_{c}$ representing the preferences on reasons derived from the case $c$ is defined by stipulating that $W<_{c} Z$ if and only if $W \subseteq X^{\bar{s}}$ and Premise $(r) \subseteq Z$.

It is easy-indeed, trivial-to verify that the preference relation derived from any particular case $c$ is transitive: whenever $X<_{c} Y$ and $Y<_{c} Z$, it follows that $X<_{c} Z$. It is not, however, a connected relation: we do not invariably have either $X<_{c} Y$ or $Y<_{c} X$-the case $c$ may tell us nothing at all about the relative strength of $X$ and $Y$. To illustrate by returning to $c_{1}$, we do not have either $\left\{f_{1}^{\delta}\right\}<_{c_{1}}\left\{f_{1}^{\pi}\right\}$ or $\left\{f_{1}^{\pi}\right\}<_{c_{1}}\left\{f_{1}^{\delta}\right\}$, for example.

Once we have defined the preference relation derived from a single case, we can then introduce a preference relation $<_{\Gamma}$ derived from an entire case base $\Gamma$ in the natural way, by stipulating that one reason is stronger than another according to the entire case base if that strength relation is supported by some particular case in the case base:

Definition 3 (Preference relation derived from a case base). Let $\Gamma$ be a case base, and suppose $W$ and $Z$ are reasons. Then the relation $<_{\Gamma}$ representing the preferences on reasons derived from the case base $\Gamma$ is defined by stipulating that $W<_{\Gamma} Z$ if and only if $W<_{c} Z$ for some case $c$ from $\Gamma$.

It is worth emphasizing that the derived preference relation $<_{\Gamma}$ is very weak, both formally and conceptually. From a formal standpoint, we should note that the preference relation derived from an entire case base, like that derived from a single case, is not connected: again we may have neither $X<_{\Gamma} Y$ nor $Y<_{\Gamma} X$. More surprisingly, this new relation is not transitive either: $X<_{\Gamma} Y$ and $Y<_{\Gamma} Z$ does not entail $X<_{\Gamma} Z$. We will return in the next section to considering the issues surrounding transitivity in more detail.

The preference relation derived from a case base is conceptually weak as well, in the sense that it might reflect very few of our ordinary judgments about strength relations among reasons. Consider, for example, a situation in which the issue at hand is the question whether an individual's residence in a foreign country qualifies as a change of fiscal domicile with respect to 
income tax. ${ }^{12}$ The plaintiff is the individual's home country, which would like to collect tax on her income; the defendant is the individual, who would prefer to pay her income taxes to the foreign country, where we can assume the rates are lower. Imagine that the fact situation contains the following factors, all favoring the defendant: the individual resigned from her old job and is now employed by a company in the foreign country; she has sold her old home and purchased a new home in the foreign country; she has sold her old car and both purchased and registered a new car in the foreign country. Suppose these three factors are represented as $f_{1}^{\delta}, f_{2}^{\delta}$, and $f_{3}^{\delta}$. In favor of the plaintiff is the single factor that the individual has maintained a registered bicycle in her home country, which she uses while visiting her parents; this factor is $f_{1}^{\pi}$.

Can we now assume that the reason $\left\{f_{1}^{\delta}, f_{2}^{\delta}, f_{3}^{\delta}\right\}$ favoring the defendant should be preferred to the reason $\left\{f_{1}^{\pi}\right\}$ favoring the plaintiff? Intuitively it would seem so; surely the mass of information about employment, residence, and automobile registration should outweigh some stray fact about bicycle registration. But as a matter of precedential constraint, not necessarily. Unless the case base $\Gamma$ contains a previous case in which bicycle registration was actually compared to at least one of the factors supporting the defendant and found to be less weighty, we do not have $\left\{f_{1}^{\pi}\right\}<_{\Gamma}\left\{f_{1}^{\delta}, f_{2}^{\delta}, f_{3}^{\delta}\right\}$. The present approach thus reflects a broadly positivist view of precedential constraint, according to which the legally sanctioned preference relations among reasons must have a basis, not simply in our everyday intuitions about which reasons are stronger than which, but in the acts of an appropriate legal authority—here, a court's decision in some precedent case. ${ }^{13}$ Of course, it is likely in the present situation that the court confronting this case would be guided by our intuitive assessment concerning weight of the conflicting reasons and therefore decide for the defendant. As a result of this decision, the intuitive assessment would be given legal standing, and it would then hold, once the case is decided and the case base is updated accordingly, that $\left\{f_{1}^{\pi}\right\}<_{\Gamma}\left\{f_{1}^{\delta}, f_{2}^{\delta}, f_{3}^{\delta}\right\}$. This is the genius of the common law-that it provides a mechanism through which our ordinary intuitions about the relative importance of various reasons are gradually filtered into legal doctrine, on an incremental basis, in reaction to particular circumstances.

We now turn to the task of defining the class of precedent rules that should be considered as binding in a particular fact situation-those with the greatest bearing on that fact situation. The definition is simple and proceeds in three steps.

12. This example is modeled on some hypothetical cases considered in Henry Prakken \& Giovanni Sartor, Modelling Reasoning with Precedents in a Formal Dialogue Game, 6 ARTIFICIAL INTELLIGENCE \& L. 231-287 (1998).

13. Note that this positivist treatment of precedential constraint in particular does not entail any view of whether the law more generally should or should not be understood in positivist terms. 
First, a rule is said to be applicable in a fact situation whenever that situation contains all the factors required by the premise of the rule:

Definition 4 (Applicable rules). Let $\Gamma$ be a case base, with $\operatorname{Rule}(\Gamma)$ the derived set of rules, and suppose $X$ is a fact situation. Then a rule $r$ from Rule $(\Gamma)$ is applicable in the fact situation $X$ if and only if Premise $(r) \subseteq X$.

Since our precedent rules are taken as defeasible, however, not every applicable rule can be classified as binding. Some will be overridden-or trumped-by stronger or preferable rules supporting the opposite side.

When is one of two conflicting precedent rules preferable to the other? The force of a precedent rule, we recall, is that the premise of that rule provides the court with a reason for deciding in favor of the side specified in its conclusion. Precedent rules themselves can therefore be placed in a preference ranking exactly in accord with the reasons they provide, so that a rule $r^{\prime}$ is ranked as preferable to the rule $r$ in the context of a case base $\Gamma$ whenever the reason Premise $\left(r^{\prime}\right)$ is ranked as preferable to the reason Premise $(r)$, according to the preference relation $<_{\Gamma}$ derived from that case base-whenever, that is, Premise $(r)<_{\Gamma} \operatorname{Premise}\left(r^{\prime}\right)$.

Given this preference ranking among rules, we can now characterize an applicable rule as trumped whenever there is another rule, also applicable, that is preferred to the original and supports the opposite side:

Definition 5 (Trumped rules). Let $\Gamma$ be a case base, with $\operatorname{Rule}(\Gamma)$ the derived set of rules and $<_{\Gamma}$ the derived preference relation, and suppose $X$ is a fact situation. Then a rule $r$ from $\operatorname{Rule}(\Gamma)$ that is applicable in $X$ is trumped in the context of the case base $\Gamma$ if and only if there is another rule $r^{\prime}$ from Rule $(\Gamma)$ that is also applicable in $X$, but which is such that (1) Premise $(r)<_{\Gamma}$ Premise $\left(r^{\prime}\right)$ and (2) Conclusion $\left(r^{\prime}\right)=\overline{\operatorname{Conclusion}(r)}$.

And once we have defined both the applicable and the trumped rules, we can introduce the idea of a binding rule quite simply, as one that is applicable but not trumped:

Definition 6 (Binding rules). Let $\Gamma$ be a case base, with $R u l e(\Gamma)$ the derived set of rules and $<_{\Gamma}$ the derived preference relation, and suppose $X$ is a fact situation. A rule $r$ from Rule $(\Gamma)$ is binding in $X$ if and only if it is triggered in the fact situation $X$ and not trumped in the context of $\Gamma$.

These concepts can be illustrated by considering the very simple case base $\Gamma_{1}=\left\{c_{1}, c_{2}\right\}$, containing the familiar case $c_{1}=\left\langle X_{1}, r_{1}, s_{1}\right\rangle$-where, once again, $X_{1}=\left\{f_{1}^{\pi}, f_{2}^{\pi}, f_{3}^{\pi}, f_{1}^{\delta}, f_{2}^{\delta}, f_{3}^{\delta}, f_{4}^{\delta}\right\}$, where $r_{1}$ is $\left\{f_{1}^{\pi}, f_{2}^{\pi}\right\} \rightarrow \pi$, and where $s_{1}$ is $\pi$-as well as the new case $c_{2}=\left\langle X_{2}, r_{2}, s_{2}\right\rangle$, where $X_{2}=$ $\left\{f_{1}^{\pi}, f_{2}^{\pi}, f_{4}^{\pi}, f_{5}^{\delta}, f_{6}^{\delta}\right\}$, where $r_{2}$ is $\left\{f_{5}^{\delta}\right\} \rightarrow \delta$, and where $s_{2}$ is $\delta$, a decision for the defendant. Now suppose that, against the background of this case base, a new fact situation $X_{3}=\left\{f_{1}^{\pi}, f_{2}^{\pi}, f_{5}^{\pi}, f_{5}^{\delta}, f_{7}^{\delta}\right\}$ comes before the court. The set Rule $\left(\Gamma_{1}\right)$ of precedent rules derived from $\Gamma_{1}$ contains $r_{1}$ and $r_{2}$; and evidently both of these two rules are applicable in the new situation, since 
we have both Premise $\left(r_{1}\right) \subseteq X_{3}$ and Premise $\left(r_{2}\right) \subseteq X_{3}$. The first of these rules, however, is trumped by the second. The two rules favor different sides, of course, with $r_{1}$ favoring the plaintiff and $r_{2}$ the defendant. And it is easy to see also that in the context of $\Gamma_{1}$ as a background case base, the reason provided by the second rule is preferable to that provided by the first: it follows from our definitions that $\left\{f_{1}^{\pi}, f_{2}^{\pi}\right\}<_{c_{2}}\left\{f_{5}^{\delta}\right\}$, from which we have $\left\{f_{1}^{\pi}, f_{2}^{\pi}\right\}<_{\Gamma_{1}}\left\{f_{5}^{\delta}\right\}$ as well-that is Premise $\left(r_{1}\right)<_{\Gamma_{1}}$ Premise $\left(r_{2}\right)$. Because both $r_{1}$ and $r_{2}$ are applicable, but $r_{1}$ is trumped, only the rule $r_{2}$ is binding in this fact situation.

\section{CONSTRAINT BY PRECEDENT}

The account of precedential constraint set out here is a version of the reason model, according to which a later court is constrained to reach a decision that is consistent, not necessarily with the rules set out in earlier cases, but with the assessments reached in those cases concerning the proper balance of reasons. In order to develop this idea, I first introduce a reason-centered notion of consistency for case bases. A later decision can then be defined as consistent with the precedents contained in a case base if it does not introduce an inconsistency into that case base.

As shown above, a case base $\Gamma$ leads to a derived preference relation $<_{\Gamma}$, where the statement $X<_{\Gamma} Y$ means that the reason $Y$ is preferred to the reason $X$ according to $\Gamma$. Such a statement is supported, of course, by some particular precedent case from $\Gamma$ in which either it was decided explicitly that the reason $Y$ itself is preferred to $X$ or else that some reason at least as weak as $Y$ is preferred to some reason at least as strong as $X$, from which it follows implicitly that $X<_{\Gamma} Y$. We therefore define the case base $\Gamma$ as inconsistent whenever there are two reasons $X$ and $Y$ for which both $X<_{\Gamma} Y$ and $Y<_{\Gamma} X$-whenever, that is, $\Gamma$ tells us both that $Y$ is preferred to $X$ and that $X$ is preferred to $Y$-and consistent otherwise:

Definition 7 (Consistent and inconsistent case bases). Let $\Gamma$ be a case base, with $<_{\Gamma}$ the derived preference relation. Then $\Gamma$ is inconsistent if and only if there are reasons $X$ and $Y$ such that $X<_{\Gamma} Y$ and $Y<_{\Gamma} X . \Gamma$ is consistent if and only if it is not inconsistent.

Is this a good definition of case base inconsistency, and so consistency, from an intuitive point of view? I think so. The condition isolated by the definition is almost certainly sufficient with respect to our intuitive notion of inconsistency-surely any case base from which it can be derived that, of two reasons, each is preferred to the other would have to be classified as inconsistent from an intuitive standpoint. But is the suggested condition also necessary? Perhaps a case base might exhibit some other anomaly that would lead us to classify it, from an intuitive standpoint, as inconsistent. Suppose, for example, that the case base contains two precedent cases of the form 
$\langle X, r, s\rangle$ and $\left\langle X, r^{\prime}, \bar{s}\right\rangle$ in which the very same fact situation leads to decisions for opposing sides; surely there is some kind of intuitive inconsistency in a case base like this. True enough, but as it turns out, this particular anomaly entails that the formal condition set out in our definition of inconsistency has been met, so that it cannot be used to challenge the claim that the formal condition is necessary:

Observation 1. Let $\Gamma$ be a case base containing two precedent cases of the form $\langle X, r, s\rangle$ and $\left\langle X, r^{\prime}, \bar{s}\right\rangle$. Then $\Gamma$ is inconsistent.

A different, slightly weaker anomaly will be shown later in the paper to entail our formal condition as well. I have not been able to find any others that do not and will therefore take our formal definitions of consistency and inconsistency for a case base as intuitively acceptable.

Given this notion of consistency, then, we can now turn to the concept of precedential constraint itself. The guiding intuition is that, in deciding a case, a constrained court is required to preserve the consistency of the background case base. More exactly, where $\Gamma$ is a consistent case base, suppose a court that is constrained by $\Gamma$ is confronted with a new fact situation $X$. Then the court is required to reach a decision on $X$ that is itself consistent with $\Gamma$ - that is, a decision that does not introduce inconsistency into the case base:

Definition 8 (Precedential constraint). Let $\Gamma$ be a consistent case base and $X$ a new fact situation confronting the court. Then precedential constraint requires the court to base its decision on some rule $r$ leading to an outcome $s$ such that the new case base $\Gamma \cup\{\langle X, r, s\rangle\}$ is itself consistent.

This notion of precedential constraint can be illustrated by returning to our previous example, in which $\Gamma_{1}=\left\{c_{1}, c_{2}\right\}$ is the background case base, with $c_{1}$ and $c_{2}$ as before, and the court is confronted with the new fact situation $X_{3}=\left\{f_{1}^{\pi}, f_{2}^{\pi}, f_{5}^{\pi}, f_{5}^{\delta}, f_{7}^{\delta}\right\}$. As shown above, the rule $r_{2}$, or $\left\{f_{5}^{\delta}\right\} \rightarrow \delta$, is the unique binding rule in this fact situation, so that as far as precedent rules are concerned, the background case base unambiguously favors a decision for the defendant. And in many situations there may indeed be a presumption that favors following a binding rule. ${ }^{14}$ Still, on the view developed here, precedential constraint does not depend on binding rules but instead on consistency with the background case base.

The court, in this situation, would of course be free to follow the binding rule $r_{2}$, leading to a decision for the defendant, and so augmenting the background case base with the new case $c_{3}=\left\langle X_{3}, r_{3}, s_{3}\right\rangle$, where the rule $r_{3}$ is simply $r_{2}$ and the outcome $s_{3}$ is $\delta$, which would in fact preserve consistency. But the court is also free to decide, for example, that the new reason $\left\{f_{5}^{\pi}\right\}$,

14. See, e.g., the discussion of "presumptive positivism" in Frederick Schauer, Is the Common Law Law?, 77 Cal. L. Rev. 455-471 (1989); and Frederick Schauer, Playing by the Rules: A Philosophical Examination of Rule-Based Decision-Making in LaW and Life (1991). 
which favors the plaintiff, is itself preferable to the various reasons presented by this fact situation for the defendant. The court might then formulate a new rule $\left\{f_{5}^{\pi}\right\} \rightarrow \pi$ and on the basis of this rule decide for the plaintiff. As a result, the background case base would be augmented with the new case $c_{4}=\left\langle X_{4}, r_{4}, s_{4}\right\rangle$, where $X_{4}$ is identical with $X_{3}$, where $r_{4}$ represents this new rule, and where $s_{4}$ is $\pi$. Again, the augmented case base resulting from this decision would remain consistent. The new case $c_{4}$ would allow us to derive, for example, the preference relation $\left\{f_{5}^{\delta}, f_{7}^{\delta}\right\}<_{c_{4}}\left\{f_{5}^{\pi}\right\}$. But this new preference relation is consistent with the others already derivable from the background case base.

What the court cannot do, however-what precedential constraint rules out-is to find for the plaintiff on the basis of some reason that does not include the new factor $f_{5}^{\pi}$, since it is a consequence of the $c_{2}$ court's decision that any such reason is less preferable than the reason $\left\{f_{5}^{\delta}\right\}$ for the defendant. Suppose, for example, that the court formulates the rule $\left\{f_{1}^{\pi}\right\} \rightarrow \pi$ and wishes to decided for the plaintiff on the basis of this rule. Such a decision would result in an augmentation of the background case base with the new case $c_{5}=\left\langle X_{5}, r_{5}, s_{5}\right\rangle$, where $X_{5}$ is again identical with $X_{3}$, where $r_{5}$ represents the new rule, and where $s_{5}$ is $\pi$. But this augmented case base would now be inconsistent. The new case $c_{5}$ would support the preference relation $\left\{f_{5}^{\delta}\right\}<_{c_{5}}\left\{f_{1}^{\pi}\right\}$, telling us that the reason $\left\{f_{1}^{\pi}\right\}$ for the plaintiff outweighs the reason $\left\{f_{5}^{\delta}\right\}$ for the defendant. But the background case base already contains the case $c_{2}$, from which we can derive the preference relation $\left\{f_{1}^{\pi}\right\}<_{c_{2}}\left\{f_{5}^{\delta}\right\}$, telling us exactly the opposite. Since a decision for the plaintiff on these grounds would therefore lead to an inconsistent case base, it is ruled out by the present account of precedential constraint. ${ }^{15}$

Having defined the core concept of precedential constraint, I now want to discuss two related issues, one briefly and one at more length.

First, it is worth noting that our core account of constraint relies on the assumption that the background case base is itself consistent to begin with. This is, of course, an unrealistic assumption. Given the vagaries of judicial decision, with a body of case law developed by a number of different courts at different places and different times, it would be surprising if any nontrivial case base were actually consistent. But in fact, this assumption

15. Although this account of precedential constraint is related to the reason model originally proposed by Lamond, supra note 5 , there are at least two significant differences between Lamond's proposal and the present account. First, at a conceptual level, Lamond sets out his reason model as an alternative to the conventional view of precedential constraint, with its emphasis on rules, while, on the present account, the roles of reasons and rules are integrated: it is reasons that function as the premises of precedent rules, and the preference ordering on rules is derived from the preference ordering on reasons. And second, although Lamond himself does not develop a precise implementation of his reason model, the account set out here does seems to differ from what he has in mind. In particular, Lamond suggests ( $i d$. at 1819) that the meaning of precedents should be understood in terms of "protected reasons" and other forms of exclusionary reasons. Although initially sympathetic to this idea, I did not, in the end, find it necessary to appeal to exclusionary reasons in developing the present account. 
is not essential. The notion of case base inconsistency at work here is not like logical inconsistency-it is local, not pervasive. A case base might be inconsistent in certain areas, providing conflicting information about the relative weight of particular reasons, while remaining consistent elsewhere. It would therefore be possible to extend the present theory of precedential constraint to apply also to inconsistent case bases by requiring of a court, not necessarily that it should preserve the consistency of a consistent case base, but only that it should refrain from introducing any new inconsistencies, which were not present before, into a case base that may already be inconsistent.

Second, we must now return to the vexed issues surrounding transitivity of the preference relation derived from an entire case base. As noted earlier, the relation $<_{\Gamma}$, introduced to represent the preferences among reasons derived from the case base $\Gamma$, is not transitive: $X<_{\Gamma} Y$ and $Y<_{\Gamma} Z$ do not entail $X<_{\Gamma} Z$. Indeed, quite the opposite. For it is easy to see from our various definitions that whenever $X<_{\Gamma} Y$, the two reasons $X$ and $Y$ must lie on opposite sides of some dispute, one favoring the plaintiff while the other favors the defendant. Hence, given $X<_{\Gamma} Y$ and $Y<_{\Gamma} Z$, we can conclude that $X$ and $Z$, both lying opposed to $Y$, must themselves favor the same side, from which it follows that $X<_{\Gamma} Z$ fails.

What blocks transitivity, then, is the assumption-built into our definition-that two reasons can be related by the $<_{\Gamma}$ relation only if they favor opposite sides. In fact, this assumption is not unnatural. The $<_{\Gamma}$ relation is built on top of the $<_{c}$ relation, representing the preferences among reasons derived from the single case $c$, and what the court decides in any single case is whether, subject to the constraints of precedent, the reasons presented for one side are or are not stronger than the reasons presented for another; any observation that a reason for one side happens to be stronger than another reason for that same side would likely be taken as a mere dictum and not authoritative in future decisions.

But even if a strength comparison between reasons favoring the same side cannot be derived from a single case, perhaps such a comparison can be derived by combining information from several cases within a case base. Suppose, for example, that our background case base contains the case $c_{6}=\left\langle X_{6}, r_{6}, s_{6}\right\rangle$, where $X_{6}=\left\{f_{1}^{\pi}, f_{1}^{\delta}\right\}$, where $r_{6}$ is the rule $\left\{f_{1}^{\pi}\right\} \rightarrow \pi$, and where $s_{6}$ is $\pi$, as well as the case $c_{7}=\left\langle X_{7}, r_{7}, s_{7}\right\rangle$, where $X_{7}=\left\{f_{1}^{\pi}, f_{2}^{\delta}\right\}$, where $r_{7}$ is the rule $\left\{f_{2}^{\delta}\right\} \rightarrow \delta$, and where $s_{7}$ is $\delta$. From these two cases, we have $\left\{f_{1}^{\delta}\right\}<_{c_{6}}\left\{f_{1}^{\pi}\right\}$ and $\left\{f_{1}^{\pi}\right\}<_{c_{7}}\left\{f_{2}^{\delta}\right\}$ 一 that is, $\left\{f_{1}^{\pi}\right\}$ is a stronger reason for the plaintiff than $\left\{f_{1}^{\delta}\right\}$ is for the defendant, and $\left\{f_{2}^{\delta}\right\}$ is a stronger reason for that defendant than $\left\{f_{1}^{\pi}\right\}$ is for the plaintiff. It is therefore tempting to conclude through a form of transitivity that $\left\{f_{2}^{\delta}\right\}$ is itself a stronger reason for the defendant than $\left\{f_{1}^{\delta}\right\}$ is-otherwise why would $\left\{f_{2}^{\delta}\right\}$ but not $\left\{f_{1}^{\delta}\right\}$ be preferred to $\left\{f_{1}^{\pi}\right\}$ ?

Now, if we were to embrace this temptation, a new, stronger form of precedential constraint would then be available. Imagine that the case base 
also contains the case $c_{8}=\left\langle X_{8}, r_{8}, s_{8}\right\rangle$, where $X_{8}=\left\{f_{2}^{\pi}, f_{1}^{\delta}\right\}$, where $r_{8}$ is the rule $\left\{f_{1}^{\delta}\right\} \rightarrow \delta$, and where $s_{8}$ is $\delta$; and suppose the court is currently confronting the fact situation $X_{9}=\left\{f_{2}^{\pi}, f_{2}^{\delta}\right\}$. An advocate for the defendant could then argue as follows:

It was concluded by the $c_{6}$ court that $\left\{f_{1}^{\pi}\right\}$ is stronger for the plaintiff than $\left\{f_{1}^{\delta}\right\}$ is for the defendant, and by the $c_{7}$ court that $\left\{f_{2}^{\delta}\right\}$ is stronger for the defendant than $\left\{f_{1}^{\pi}\right\}$ is for the plaintiff. Therefore, combining these results by transitivity, it follows that $\left\{f_{2}^{\delta}\right\}$ must stronger for the defendant than $\left\{f_{1}^{\delta}\right\}$. Now, it was also concluded by the $c_{8}$ court that $\left\{f_{1}^{\delta}\right\}$ itself is sufficient to guarantee a decision for the defendant over $\left\{f_{2}^{\pi}\right\}$ for the plaintiff. Therefore, since we have already seen that $\left\{f_{2}^{\delta}\right\}$ is stronger for the defendant than $\left\{f_{1}^{\delta}\right\}$, it follows that $X_{9}$ should be decided for the defendant as well.

This argument is, as I say, tempting, and there is no technical difficulty in extending our definitions to support the notion of constraint it suggests. To do so, we need only move from the familiar relation $<_{\Gamma}$, introduced in Definition 3 to represent the intransitive preferences derived from the case base $\Gamma$, to a stronger relation-say, $\prec_{\Gamma}$ - defined simply as the transitive closure of the previous intransitive relation. More exactly, the relation $\prec_{\Gamma}$, representing the transitive preferences derived from $\Gamma$, can be defined by stipulating that, where $W$ and $Z$ are reasons, then $W \prec_{\Gamma} Z$ if and only if there is a sequence of reasons $X_{1}, X_{2}, \ldots X_{n}$ such that (i) $X_{1}=W$ and $X_{n}=Z$, and (ii) $X_{i}<_{\Gamma} X_{i+1}$ for $i$ from 1 through $n-1$. Using this new idea of transitive preference, we could then mirror our Definitions 7 and 8 ideas of consistency and constraint to arrive at their transitive analogues by stipulating: first, that the case base $\Gamma$ possesses the property of transitive consistency if and only if there are no reasons $W$ and $Z$ such that $W \prec_{\Gamma} Z$ and $Z \prec_{\Gamma} W$; and second, that transitive precedential constraint requires a court confronting a new fact situation $X$ against the background of a transitive consistent case base $\Gamma$ to reach a decision based on a rule $r$ leading to an outcome $s$ such that $\Gamma \cup\{\langle X, r, s\rangle\}$ preserves transitive consistency.

The resulting transitive theory of precedential constraint would then allow us to validate the advocate's argument for the defendant in the situation $X_{9}=\left\{f_{2}^{\pi}, f_{2}^{\delta}\right\}$. The case $c_{8}$ tells us that $\left\{f_{2}^{\pi}\right\}<_{c_{8}}\left\{f_{1}^{\delta}\right\}$, and as we have already seen, $c_{6}$ and $c_{7}$ establish that $\left\{f_{1}^{\delta}\right\}<_{c_{6}}\left\{f_{1}^{\pi}\right\}$ and $\left\{f_{1}^{\pi}\right\}<_{c_{7}}\left\{f_{2}^{\delta}\right\}$. If we take $\Gamma$ as the background case base containing each of these cases, we therefore know that $\left\{f_{2}^{\pi}\right\}<_{\Gamma}\left\{f_{1}^{\delta}\right\}$, that $\left\{f_{1}^{\delta}\right\}<_{\Gamma}\left\{f_{1}^{\pi}\right\}$, and that $\left\{f_{1}^{\pi}\right\}<_{\Gamma}\left\{f_{2}^{\delta}\right\}$. From this, our new definition of transitive preference allows us to conclude that $\left\{f_{2}^{\pi}\right\} \prec_{\Gamma}\left\{f_{2}^{\delta}\right\}$. Transitive precedential constraint thus forces a decision in $X_{9}$ for the defendant, since a decision for the plaintiff would then establish that $\left\{f_{2}^{\delta}\right\} \prec_{\Gamma}\left\{f_{2}^{\pi}\right\}$ as well and so would lead to a transitive inconsistency in the case base. 
Still, even though this kind of argument is tempting and even though the present account can be extended in a straightforward way to support the transitive reasoning necessary to validate the argument, I am not entirely convinced that we should allow this extension. My concerns have to do with transitivity itself and in particular with the way in which transitivity allows the preference relations among different reasons established by different courts to be amalgamated into a sort of group preference, even though the various reasons involved may never have been considered together by any single court-as in our example, where the separate judgments of the $c_{6}, c_{7}$, and $c_{8}$ courts are combined to support the overall judgment that $\left\{f_{2}^{\delta}\right\}$ outweighs $\left\{f_{2}^{\pi}\right\}$ even though no case presenting both of these reasons together has yet been considered.

The appeal to transitive reasoning introduces a number of complex issues concerning the amalgamation of judgments and preferences from different sources. ${ }^{16}$ In order to avoid these additional complexities, I concentrate in this paper only on the core account of precedential constraint set out in Definitions 3, 7, and 8, leaving the promises and problems associated with any possible transitive extension of this core account for another time.

\section{CASE BASE DYNAMICS}

I now want to consider how two of the most important concepts from the traditional theory of precedent - the concepts of following and of distinguishing a precedent — can be accommodated within the present framework. The more general goal is to understand the options available to the court under various circumstances, and also the way in which the case base and its associated constraints evolve when one of these options is selected-that is, the dynamics of case base update.

Imagine, then, that a court constrained by the precedents from a consistent case base $\Gamma$ is confronted with a new problem situation $X$, and suppose to begin with that none of the rules belonging to $R u l e(\Gamma)$ is even applicable to $X$. A situation like this is our theoretical analogue to the legal notion of a case of first impressions, presenting-in the paradigm case-issues that have not previously been addressed within the law, so that the established rules of precedent have no bearing. ${ }^{17}$ The court is therefore free to assess the issues in whatever way it thinks best, to formulate a rule $r$ supporting an outcome $s$, and to reach a decision of the form $\langle X, r, s\rangle$. This decision, of

16. Any reader who is unfamiliar with these issues is invited to consult Lewis Kornhauser \& Lawrence Sager, Unpacking the Court, 96 YALE L.J. 82-117 (1986), and the extensive literature on judgment aggregation spawned by that paper, in addition to the standard work in economics on the derivation of group preferences from individual preferences.

17. See, e.g., the discussion in Rupert Cross, Precedent in English Law, 2d ed. (1968), at 190195; at times other, more complicated situations are also referred to as cases of first impressions, such as situations in which multiple precedent rules apply yet none clearly trumps the other or situations in which entirely novel factors are present. 
course, leads to $\Gamma \cup\{\langle X, r, s\rangle\}$ as the updated case base, and fortunately any such decision is guaranteed to preserve consistency. In such a case of first impressions, there is no precedential constraint at all:

Observation 2. Let $\Gamma$ be a consistent case base and suppose $X$ is a fact situation in which none of the rules from $\operatorname{Rule}(\Gamma)$ are applicable. Then $\Gamma \cup$ $\{\langle X, r, s\rangle\}$ is also consistent, where $r$ is any newly formulated rule applicable in $X$ and supporting $s$ as an outcome.

Next, still imagining that a court constrained by $\Gamma$ is confronted with a new situation $X$, let us suppose that some precedent rule from $\operatorname{Rule}(\Gamma)$ is in fact binding in this situation. Then, according to the traditional theory, any court has the option of either following or distinguishing the binding precedent rule. ${ }^{18}$

Where $r$ is such a binding rule from $\operatorname{Rule}(\Gamma)$, supporting the outcome $s$, we can say that the court follows this rule whenever it reaches a decision of the form $\langle X, r, s\rangle$, generating $\Gamma \cup\{\langle X, r, s\rangle\}$ as the updated case base. As shown above, precedential constraint is not, on the present theory, carried through precedent rules, so one might wonder what role these rules do play. Here is one answer. Although satisfying precedential constraint does not require following a binding rule, it turns out that following a binding rule is sufficient to guarantee the satisfaction of precedential constraint; any decision that follows a binding rule preserves consistency:

Observation 3. Let $\Gamma$ be a consistent case base, with $\operatorname{Rule}(\Gamma)$ the derived set of rules, and suppose $X$ is a fact situation in which some rule $r$ from $\operatorname{Rule}(\Gamma)$, supporting the outcome $s$, is binding. Then the case base $\Gamma \cup\{\langle X, r, s\rangle\}$ is also consistent.

We can say that the court distinguishes the binding rule $r$, by contrast, whenever it either follows or formulates another rule $r^{\prime}$ supporting the opposite outcome $\bar{s}$, leading to a decision of the form $\left\langle X, r^{\prime}, \bar{s}\right\rangle$ and so generating $\Gamma \cup\left\{\left\langle X, r^{\prime}, \bar{s}\right\rangle\right\}$ as the updated case base. And of course, while, as we have seen, a court is guaranteed to preserve consistency whenever it follows a binding rule, there is no such guaranteed with distinguishing; the operation must be performed with some care, guided by the constraints of precedent.

Both the ideas of following and of distinguishing a binding rule are illustrated by our previous example, in which a court constrained by the case base $\Gamma_{1}=\left\{c_{1}, c_{2}\right\}$ confronts the new fact situation $X_{3}=\left\{f_{1}^{\pi}, f_{2}^{\pi}, f_{5}^{\pi}, f_{5}^{\delta}, f_{7}^{\delta}\right\}$. Here, as we noted, the rule $r_{2}$, or $\left\{f_{5}^{\delta}\right\} \rightarrow \delta$, is the unique binding rule, so that the court follows this rule if it reaches the decision $c_{3}=\left\langle X_{3}, r_{3}, s_{3}\right\rangle$, where $r_{3}$ is $r_{2}$ and $s_{3}$ is $\delta$, leading to $\Gamma_{1} \cup\left\{\left\langle X_{3}, r_{3}, s_{3}\right\rangle\right\}$ as the updated case

18. Of course, depending on the court's standing in the judicial hierarchy, it has the further option of overruling the precedent. I do not consider this further option in this paper. 
base. But as we also noted, the court is likewise free to formulate and apply the new rule $r_{4}$, or $\left\{f_{5}^{\pi}\right\} \rightarrow \pi$, leading to the decision $c_{4}=\left\langle X_{4}, r_{4}, s_{4}\right\rangle$, where $X_{4}$ is $X_{3}$ and $s_{4}$ is $\pi$, and so to $\Gamma_{1} \cup\left\{\left\langle X_{4}, r_{4}, s_{4}\right\rangle\right\}$ as the updated case base. In that circumstance, we would now say that the court distinguishes the binding rule $r_{2}$.

With these notions of following and distinguishing a rule before us, I can now make three points.

First, it follows at once from Observations 2 and 3 that a court presented with a new fact situation, will always be in a position to comply with the constraints of precedent-the court will never be forced to introduce an inconsistency into the case base. For either no rule from the background case base will be applicable in the new situation or some binding rule will be applicable. ${ }^{19}$ If no rule is applicable, then it follows from Observation 2 that any decision reached by the court will preserve consistency. If some binding rule is applicable, then it follows from Observation 3 that the court can preserve consistency simply by following that rule.

Second, although the traditional concepts of following and distinguishing a precedent rule can be accommodated within the framework set out here, the present framework is more general, allowing us to understand options available to a court that do not seem to fall naturally within the traditional classification. To illustrate, we return to the example of a court confronting the situation $X_{3}=\left\{f_{1}^{\pi}, f_{2}^{\pi}, f_{5}^{\pi}, f_{5}^{\delta}, f_{7}^{\delta}\right\}$ against the background of the case base $\Gamma_{1}=\left\{c_{1}, c_{2}\right\}$, with $r_{2}$, or $\left\{f_{5}^{\delta}\right\} \rightarrow \delta$, as a binding rule. The rule $r_{2}$, of course, was formulated in the context of the precedent case $c_{2}$, with $X_{2}=\left\{f_{1}^{\pi}, f_{2}^{\pi}, f_{4}^{\pi}, f_{5}^{\delta}, f_{6}^{\delta}\right\}$ as its fact situation. What the $c_{2}$ court is telling us with its decision, then, is that the reason provided by $\left\{f_{5}^{\delta}\right\}$ for the defendant outweighs the reason $\left\{f_{1}^{\pi}, f_{2}^{\pi}, f_{4}^{\pi}\right\}$ present in $X_{2}$ for the plaintiff.

Now, we have previously imagined that the current court, confronted with $X_{3}$, might conclude that the new reason $\left\{f_{5}^{\pi}\right\}$, which was not present in $X_{2}$, is preferred to the previous reason $\left\{f_{5}^{\delta}\right\}$ for the defendant, and so decide $X_{3}$ for the plaintiff. But we could likewise suppose that the current court, while still recognizing that the reason $\left\{f_{5}^{\pi}\right\}$ for the plaintiff is preferred to $\left\{f_{6}^{\delta}\right\}$ for the defendant, also feels that the new reason $\left\{f_{7}^{\delta}\right\}$ for the defendant, also present here for the first time, itself outweighs $\left\{f_{5}^{\pi}\right\}$. The current court might then reach the decision $c_{10}=\left\langle X_{10}, r_{10}, s_{10}\right\rangle$, where $X_{10}$ is $X_{3}$, where $s_{10}$ is $\delta$, and where $r_{6}$ represents the new rule $\left\{f_{7}^{\delta}\right\} \rightarrow \delta$. In this case, although both the decision and the train of thought leading to it seem to make perfect sense, it would be hard to describe the court's decision in terms of the traditional vocabulary of following or distinguishing a rule. The court is not following the binding rule $r_{2}$, or $\left\{f_{5}^{\delta}\right\} \rightarrow \delta$, since its decision is not based on this rule, and indeed, it recognizes that the situation presents the reason

19. We can assume that the set of precedent rules is finite, so that not every applicable rule can be trumped by another rule; as a result, if any rule is applicable to a fact situation, some rule must be binding-applicable and untrumped. 
$\left\{f_{5}^{\pi}\right\}$ for the plaintiff, which outweighs the reason $\left\{f_{5}^{\delta}\right\}$ for the defendant, on which the rule $r_{2}$ is based. But the court is not distinguishing the rule $r_{2}$ either, since it reaches a decision for the side that is favored by that rule.

Third, and finally, the present framework allows us to understand a feature of the common law that can seem very puzzling from a more traditional perspective-the idea that simply following a precedent rule can lead to a change in the law. This idea is often alluded to in the legal literature. Edward Levi, for example, writes that "the rules change from case to case and are remade with each case," and later that "the rules change as the rules are applied." ${ }^{20}$ And Simpson likewise, after discussing the operations of distinguishing and following a precedent rule, writes that "the development of the law is normally brought about by just these two activities," which leads him to a sort of paradox: "The legal process is conceived of as conditioned by rules, yet in a sense the rules change from case to case; the very point in having a system of rules to ensure consistency in decision seems to be frustrated if the rules themselves lack fixity."21

These remarks can be hard to understand. It is easy enough to see how distinguishing a precedent rule might introduce a change into the law. As shown above, distinguishing a rule often involves introducing a new rule into the case base. But if a court simply follows a precedent rule-if it does no more than draw a rule from some precedent case and apply that same rule to a new fact situation-how can we say that the rules are changed, or that the law is affected at all?

The current account gives us the resources to answer this question, as long as we take phrases such as "the rules change as the rules are applied" to refer, not necessarily to the set of precedent rules themselves, but in a more metaphorical way to the precedential constraints generated by the underlying case base. In that case, although simply following a familiar precedent rule, and applying it in a new situation does not lead to any modifications in the set of rules derived from a case base, it does indeed affect the precedential constraints generated by that case base. For these constraints depend not on the set of precedent rules but on consistency with the background case base. Consistency in turn is defined in terms of the preference ordering on reasons that is generated by the case base. And as it turns out, even following a precedent rule-simply applying a familiar rule in a new situation-can change the preference ordering on reasons in a way that affects precedential constraint. For each time a familiar rule is followed in a new case, the court makes the decision that certain reasons that might conceivably have been judged as strong enough to override that rule are in fact not strong enough. These decisions, encoded in new cases, then modify the preference relations derived from the case base, which affects

20. See Edward Levi, An Introduction to Legal Reasoning (1949), at 2-4.

21. See Simpson, supra note 2, at 172, who himself cites LEVI, supra note 20. 
the options open to the court when it encounters those same reasons again in the future.

The point can be illustrated by returning once again to our familiar example, in which a court constrained by the case base $\Gamma_{1}=\left\{c_{1}, c_{2}\right\}$ confronts the new fact situation $X_{3}=\left\{f_{1}^{\pi}, f_{2}^{\pi}, f_{5}^{\pi}, f_{5}^{\delta}, f_{7}^{\delta}\right\}$. Now, as we have seen, even though $r_{2}$, or $\left\{f_{5}^{\delta}\right\} \rightarrow \delta$, is the unique binding rule in this new situation, precedential constraints allow the court to distinguish this rule, arriving instead at the decision $c_{4}=\left\langle X_{4}, r_{4}, s_{4}\right\rangle$, where $r_{4}$ is $\left\{f_{5}^{\pi}\right\} \rightarrow \pi$.

Suppose, however, that, prior to confronting the fact situation $X_{3}$, the court is first faced with the fact situation $X_{11}=\left\{f_{5}^{\pi}, f_{6}^{\pi}, f_{5}^{\delta}, f_{7}^{\delta}\right\}$, again with $r_{2}$ as the unique binding rule; but here it decides simply to apply this rule, resulting in the decision $c_{11}=\left\langle X_{11}, r_{11}, s_{11}\right\rangle$, where $r_{11}$ is $r_{2}$ and $s_{11}$ is $\delta$. The court would then be confronting the new situation $X_{3}$ against the background of the case base $\Gamma_{2}=\left\{c_{1}, c_{2}, c_{11}\right\}$ rather than the case base $\Gamma_{1}$. Of course, since $c_{11}$ is decided by the application of a rule already present in $c_{2}$, the set of rules derived from these two case bases is identical: $\operatorname{Rule}\left(\Gamma_{2}\right)$ is simply Rule $\left(\Gamma_{1}\right)$. Nevertheless, although the rules remain the same, the addition of $c_{11}$ does affect the derived priority ordering: $<_{\Gamma_{2}}$ is not identical to $<_{\Gamma_{1}}$. And this new priority ordering then changes precedential constraint in such a way that the court, when faced with the situation $X_{3}$, would no longer be free to reach the decision $c_{4}=\left\langle X_{4}, r_{4}, s_{4}\right\rangle$. Why? Well, we can conclude from the court's decision in $c_{11}$ that the reason $\left\{f_{5}^{\delta}\right\}$ for the defendant is preferred to the reason $\left\{f_{5}^{\pi}\right\}$ for the plaintiff-that is, $\left\{f_{5}^{\pi}\right\}<_{c_{11}}\left\{f_{5}^{\delta}\right\}$, from which it follows that $\left\{f_{5}^{\pi}\right\}<_{\Gamma_{2}}\left\{f_{5}^{\delta}\right\}$. But the decision $c_{4}$ would tell us exactly the opposite, that the reason $\left\{f_{5}^{\pi}\right\}$ for the plaintiff is preferred to the reason $\left\{f_{5}^{\delta}\right\}$ for the defendant-that is, $\left\{f_{5}^{\delta}\right\}<_{c_{4}}\left\{f_{5}^{\pi}\right\}$, from which it would follow that $\left\{f_{5}^{\delta}\right\}<_{\Gamma_{2}}\left\{f_{5}^{\pi}\right\}$. The decision $c_{4}$ is therefore inconsistent with $\Gamma_{2}$ or with any other case base containing $c_{11}$ and so would be ruled out by precedential constraint. ${ }^{22}$

22. Lamond, supra note 5, makes exactly this point - that following as well as distinguishing a previous precedent rule can change the law. However, the way in which he develops this idea indicates, I believe, a problem with his picture of case base dynamics and the evolution of legal doctrine. On Lamond's view, the doctrine provided by a precedent rule, or ratio, consists, not only in the particular reason carried by that rule, but in the set of facts that have been judged as insufficient in strength to defeat that reason. Following a rule thus leads to a change in legal doctrine because: "every time a precedent is followed, further facts are added to the list of those regarded as insufficient to defeat the reason provided by the ratio" ( $\mathrm{id}$. at 17 ; see also $i d$. at 20). To illustrate with our example, the doctrine provided by the case $c_{2}$ would, on this view, consist in the rule $r_{2}$, or $\left\{f_{5}^{\delta}\right\} \rightarrow \delta$, along with the list $\left\{f_{1}^{\pi}, f_{2}^{\pi}, f_{4}^{\pi}\right\}$ of factors judged by the $c_{2}$ court as insufficient in strength to defeat this rule; the application of the same rule in the case of $c_{11}$ would change the doctrine by expanding this list to $\left\{f_{1}^{\pi}, f_{2}^{\pi}, f_{4}^{\pi}, f_{5}^{\pi}, f_{6}^{\pi}\right\}$, which also includes the new factors judged by the $c_{11}$ court as insufficient to defeat $r_{2}$. I feel, however, that the use of a simple list of individual factors that are viewed as insufficient to override a rule is not adequate. For this reason, I rely here on a more general preference relation to represent strength comparisons among conflicting reasons-sets of factors, rather than individual factors-and it is this relation that is then updated as rules are applied. On my view, then, the doctrine of $c_{2}$ consists in the rule $r_{2}$ together with the information that $\left\{f_{5}^{\delta}\right\}$ is preferred to the reason $\left\{f_{1}^{\pi}, f_{2}^{\pi}, f_{4}^{\pi}\right\}$ or any of its subsets, so that none of these reasons can 


\section{THE RESULT MODEL}

This section compares aspects of the current account of precedential constraint to a version of the result model, according to which a body of precedent cases constrains a later court only when that court is presented with an a fortiori fact situation-a situation that is at least as strong for the winning side of some precedent case as that precedent case itself. Obviously, this model presupposes some ordering through which different fact situations can be compared in strength for one side or another. As mentioned earlier, Alexander objects to the result model on the grounds that any such ordering would be unattractive and perhaps incoherent, but I propose elsewhere a strength ordering that I believe avoids these objections and allow us to provide a sensible, if limited, defense of the result model. ${ }^{23}$

I do not intend to review these various arguments here but only to compare the notion of constraint derived from the result model-which I refer to here as a fortiori constraint - with the concept of precedential constraint set out in the current paper. The more general goal is to show how the appeal to reasons and rules can enrich the notion of constraint that is derived simply from results.

We begin with the proposed strength ordering on fact situations, which is motivated in more detail in my earlier paper. ${ }^{24}$ The idea is that a fact situation $Y$ presents a case for the side $s$ that is at least as strong as that presented by the fact situation $X$ whenever $Y$ contains all the factors from $X$ that support $s$ and $X$ contains all the factors from $Y$ that support $\bar{s}$, the opposite side. If we let $\leq^{s}$ represent the strength ordering for the side $s$, this idea can then be defined formally as follows:

Definition 9 (Strength for a side). Let $X$ and $Y$ be fact situations. Then $Y$ is at least as strong as $X$ for the side $s$-written, $X \leq^{s} Y$-if and only if $X^{s} \subseteq Y^{s}$ and $Y^{\bar{s}} \subseteq X^{\bar{s}}$.

To illustrate, consider the fact situations $X_{12}=\left\{f_{1}^{\pi}, f_{1}^{\delta}, f_{2}^{\delta}\right\}$ and $X_{13}=$ $\left\{f_{1}^{\pi}, f_{2}^{\pi}, f_{1}^{\delta}\right\}$. We then have $X_{12} \leq^{\pi} X_{13}$, since $X_{13}$ contains all the factors from $X_{12}$ that support $\pi$, and $X_{12}$ contains all the factors from $X_{13}$ that support $\delta$; and we can see likewise that $X_{13} \leq \delta X_{12}$. This definition, I have argued, conforms to our intuitions, and it exhibits a number of plausible formal properties as well.

defeat that rule; the case $c_{11}$ then adds the further information that $\left\{f_{5}^{\delta}\right\}$ is likewise preferred to $\left\{f_{5}^{\pi}, f_{6}^{\pi}\right\}$ or its subsets. But all of this is consistent with the idea that a court might eventually decide that $\left\{f_{5}^{\delta}\right\}$ is not preferred to, say, the reason $\left\{f_{4}^{\pi}, f_{5}^{\pi}\right\}$ —which contains a pair of potential defeaters, one from each of the two cases, which had not yet been considered in combination. It is hard to see how this latter possibility could be captured in Lamond's list notation, which refers only to individual factors rather than to reasons, or sets of factors.

23. See Alexander, Constrained, supra note 1 , for his initial attack of the result model, and Horty supra note 4, for my defense; Alexander and Sherwin respond to some of my arguments in Larry Alexander \& Emily Sherwin, Judges as Rule Makers, in COMMON LaW THEORY 27-50 (Douglas Eldin ed., 2007).

24. See Horty supra note 4. 
Given this notion of strength, we can now note, as an aside, that it allows us to generalize Observation 1 , according to which a certain anomaly in a case base entails inconsistency. What this observation shows is that any case base containing two cases in which the same fact situation $X$ is decided for two different sides, both $s$ and $\bar{s}$, must be inconsistent, in our formal sense. We can now see that a case base is likewise inconsistent if it contains cases in which one fact situation $X$ is decided for the side $s$ while another fact situation $Y$, at least as strong for $s$ as $X$, happens to be decided for $\bar{s}$ :

Observation 4. Let $\Gamma$ be a case base containing two precedent cases of the form $\langle X, r, s\rangle$ and $\left\langle Y, r^{\prime}, \bar{s}\right\rangle$ where $X \leq^{s} Y$. Then $\Gamma$ is inconsistent.

Since any fact situation is at least as strong as itself for either side, this result generalizes our earlier observation, and so provides further support that our formal notion of inconsistency is intuitively correct.

Once this strength ordering $\leq^{s}$ is in place, it is then a straightforward matter to define the concept of a fortiori constraint, the notion of constraint at work in the result model of precedent. The idea, once again, is that a court faced with a fact situation $X$ should reach a decision for the side $s$ whenever $X$ is at least as strong for $s$ as some precedent case that was itself decided for that side-whenever, that is, $X$ is at least as strong for $s$ as the fact situation of some precedent case whose outcome was a decision for $s$ :

Definition 10 (A fortiori constraint). Let $\Gamma$ be a case base and $X$ a new fact situation confronting the court. Then a fortiori constraint requires the court to reach a decision in $X$ for the side $s$ if and only if there is some precedent case $c$ from $\Gamma$ such that Outcome $(c)=s$ and Facts $(c) \leq^{s} X$.

To illustrate, suppose the background case base $\Gamma$ contains the familiar case $c_{1}=\left\langle X_{1}, r_{1}, s_{1}\right\rangle$, where $X_{1}=\left\{f_{1}^{\pi}, f_{2}^{\pi}, f_{3}^{\pi}, f_{1}^{\delta}, f_{2}^{\delta}, f_{3}^{\delta}, f_{4}^{\delta}\right\}$, where the rule $r_{1}$ is $\left\{f_{1}^{\pi}, f_{2}^{\pi}\right\} \rightarrow \pi$, and where the outcome $s_{1}$ is $\pi$; and imagine that the court is confronting the new fact situation $X_{14}=\left\{f_{1}^{\pi}, f_{2}^{\pi}, f_{3}^{\pi}, f_{1}^{\delta}\right\}$. Of course, Outcome $\left(c_{1}\right)=\pi$ and Facts $\left(c_{1}\right)=X_{1}$, and it is easy to see that $X_{1} \leq{ }^{\pi} X_{14}$, since $X_{14}$ contains all the factors from $X_{1}$ that favor $\pi$ and fewer that favor $\delta$. The notion of a fortiori constraint therefore requires that $X_{14}$ should be decided for the plaintiff, since $\Gamma$ contains the case $c_{1}$ with Outcome $\left(c_{1}\right)=\pi$ and Facts $\left(c_{1}\right) \leq^{\pi} X_{14}$.

Now, what is the relation between this notion of a fortiori constraint, derived from the result model, and the concept of precedential constraint advanced in this paper, which involves reasons and rules? There are two initial points to make. The first is that a fortiori constraint entails precedential constraint in the sense that in any situation in which a fortiori constraint requires an outcome, a decision for some particular side, precedential constraint requires that same outcome:

Observation 5. Let $\Gamma$ be a consistent case base and $X$ a new fact situation confronting the court, and suppose a fortiori constraint requires the court 
to reach a decision for the side $s$ in the situation $X$. Then precedential constraint also requires the court to reach a decision for the side $s$.

The second point is that the converse entailment does not hold: there are some situations in which precedential constraint requires an outcome that is not required by a fortiori constraint. Suppose, for example, that the background case base contains the single precedent case $c_{1}$, as above, and that the court is confronted with the new fact situation $X_{15}=\left\{f_{1}^{\pi}, f_{2}^{\pi}, f_{1}^{\delta}\right\}$. It is then easy to see that the relation Facts $\left(c_{1}\right) \leq^{\pi} X_{15}$ fails-the fact situation $X_{15}$ is not stronger for the plaintiff than $X_{1}$, since, although $X_{15}$ contains fewer factors than $X_{1}$ that favor $\delta$, it contains fewer that favor $\pi$ as well. The court therefore is not required by a fortiori constraint to reach a decision for the plaintiff in this situation.

On the other hand, the court would be required by precedential constraint to decide for the plaintiff in the fact situation $X_{15}$. After all, the rule of the precedent case $c_{1}$ is $r_{1}$, or $\left\{f_{1}^{\pi}, f_{2}^{\pi}\right\} \rightarrow \pi$. What the $c_{1}$ court is telling us with its decision for the plaintiff, then, is that the reason $\operatorname{Premise}\left(r_{1}\right)=\left\{f_{1}^{\pi}, f_{2}^{\pi}\right\}$ outweighs the reason $X_{1}^{\delta}=\left\{f_{1}^{\delta}, f_{2}^{\delta}, f_{3}^{\delta}, f_{4}^{\delta}\right\}$, or any of its subsets. In particular, we have $\left\{f_{1}^{\delta}\right\}<_{c_{1}}\left\{f_{1}^{\pi}, f_{2}^{\pi}\right\}$-that is, the reason $\left\{f_{1}^{\pi}, f_{2}^{\pi}\right\}$ for the plaintiff outweighs the reason $\left\{f_{1}^{\delta}\right\}$ for the defendant, according to the $c_{1}$ court. In the new situation $X_{15}$, a decision for the defendant would carry exactly the opposite information-that the reason $\left\{f_{1}^{\delta}\right\}$ for the defendant outweighs the reason $\left\{f_{1}^{\pi}, f_{2}^{\pi}\right\}$ for the plaintiff-thus introducing an inconsistency into the case base. Therefore, since a decision for the defendant in this situation leads to inconsistency, precedential constraint requires a decision for the plaintiff.

Putting these two points together, we can conclude that the concept of a fortiori constraint at work in the result model entails but is not entailed by the notion of precedential constraint advanced here: in any situation in which a fortiori constraint requires an outcome, precedential constraint requires that same outcome, but there are some situations in which precedential constraint requires an outcome that a fortiori constraint does not. Furthermore, we can begin to see how it is, exactly, that the explicit appeal to rules, or reasons, can enhance the notion of constraint that is derived purely from results.

Put abstractly, the force of a court's decision for $s$ in the situation $X$ according to the result model is simply that $X^{\bar{s}}$ is outweighed by $X^{s}-$ that the strongest reason favoring $\bar{s}$ is outweighed by the strongest reason favoring $s$. This decision thus constrains only those future cases in which the reasons favoring $\bar{s}$ are no stronger than $X^{\bar{s}}$ and the reasons favoring $s$ are at least as strong as $X^{s}$. On the present theory, by contrast, the force of a court's decision for $s$ in the situation $X$ is that $X^{\bar{s}}$ is outweighed not simply by $X^{s}$ but by Premise $(r)$, where $r$ is the rule appealed to in the decision-that the strongest reason favoring $\bar{s}$ is outweighed, not simply by the strongest available reason favoring $s$, but by the premise of the 
rule supporting a decision for $s$. Since the premise of some rule favoring $s$ can be considerably weaker than the strongest reason supporting $s-$ that is, since Premise $(r) \subseteq X^{s}$-the precedent will have broader reach. The additional expressive resources provided by explicitly formulated rules or reasons thus allow courts to weaken the conditions necessary for constraint and so formulate precedents with greater generality.

The same point can be seen from the other side as well. Rather than considering the way in which rules add expressive resources to the result model, we can instead view the result model itself as a special case of the present account in which rules are restricted to a particular form. Consider again a fact situation $X$ that is decided for $s$. As we have seen, the present account allows the court, by formulating a rule $r$, to broaden the scope of its decision by citing as its reason, not necessarily $X^{s}$, the strongest possible reason favoring $s$, containing every factor from $X$ that favors this result, but only Premise $(r)$, a subset of this consideration. But suppose the court does, in fact, cite as the reason for its decision the very strong consideration $X^{s}$ by formulating a rule of the form $X^{s} \rightarrow s$. In that case, as it turns out, the decision constrains exactly the same future cases under both the present theory and the result model. If we now imagine that courts are limited to rules of this special form, the present theory of precedential constraint collapses into the result model:

Observation 6. Consider only cases $\langle X, r, s\rangle$ in which the rule $r$ has the form $X^{s} \rightarrow s$. Let $\Gamma$ be a consistent set of such cases, and suppose that $Y$ is a new fact situation confronting the court. Then a fortiori constraint requires the court to reach a decision for some particular side in this situation if and only if precedential constraint requires a decision for the same side.

This result suggests two lines of interpretation, which I simply mention here. It provides us, first, with a way of interpreting within the present framework the occasional case in which a court reaches some decision on a the basis of a fact situation but no rule is explicitly supplied: if the fact situation is $X$ and the court reaches a decision for the side $s$, we can thus imagine the court as working with an implicit rule of the form $X^{s} \rightarrow s$, according to which the entire set of factors from $X$ favoring the side $s$ is taken as the premise of a rule leading to $s$ as its conclusion. And second, the result also suggests a charitable interpretation of Arthur Goodhart's famous "material facts" version of the rule of a case. ${ }^{25}$ On Goodhart's view, legal decisions are often influenced by principles of which the court is unaware, or which the court misunderstands; accordingly, he places less emphasis on the rule actually formulated by the court to justify its decision and more emphasis on an implicit rule that has as its premise the material facts of the case and as its conclusion the outcome arrived at by the court. But surely not all the material facts of a given case can be taken to support its outcome. If

25. See Arthur Goodhart, Determining the Ratio Decidendi of a Case, 40 YALE L.J. 161-183 (1930). 
the fact situation is $X$ and the outcome arrived at by the court is $s$, only those facts belonging to $X^{s}$ actually support $s$ as an outcome; the others-those facts belonging to $X^{\bar{s}}$-instead support $\bar{s}$, the opposite outcome. Goodhart can thus be interpreted as holding that regardless of the rule explicitly formulated by the court, the principle actually guiding the court's decision for $s$ in the situation $X$ is simply the rule $X^{s} \rightarrow s$, according to which the material facts from $X$ that favor $s$ provide a reason for $s$, and a stronger reason than those that favor the opposite side.

\section{DISCUSSION}

My goal in this paper has been to present a new account of precedential constraint that unifies certain previous accounts from the literature-the rule, result, and reasons models. The account described here is precise, and it is set out within a representational framework, due to Ashley and his colleagues, that has already shown itself to be useful in both analytic and empirical studies of legal precedent.

I would like to think that this account could be developed into a more general theory of precedential reasoning, but that would require a good deal of work along both defensive and constructive lines. Defensively, the present treatment of precedent rules-balanced, as it is, in the center-is vulnerable to attack from both the left and the right. On the left, there are those who feel that rules play no real role in precedential constraint, including writers in the tradition of legal realism, of course, but also Ashley himself, whose very successful empirical and educational work on precedent involves no appeal to rules whatsoever. And on the right, there are those, such as Alexander and Sherwin, who recognize the importance of precedent rules but argue that coherence requires these rules to be even stronger than those at work here-strict rather than defeasible. From a constructive standpoint, the goal of precision has forced a number of limitations in the present treatment that would need to be generalized in several directions. I close by mentioning three of these.

To begin with, the fact situations at work here are specified only in terms of the factors they contain, not the factors they fail to contain; but the explicit absence of a factor is often as important to the meaning of a case as its presence. The current representation of a fact situation simply as a set of positive factors leaves us with no middle ground: if a factor is not listed as present in a fact situation, it must be regarded as absent. Indeed, this perspective is often adopted by legal theorists: Raz, for example, suggests that it is reasonable to suppose that a case can be characterized as one in which not- $F$ whenever "there is no record whether it was a case of $F$ or of not-F." ${ }^{26}$ This style of reasoning-from the absence of positive information

26. RAZ, supra note 2 , at 187. 
to the presence of negative information-is known in the computer science literature as "closed-world reasoning." It is certainly appropriate in some situations: if the Air France flight schedule does not explicitly list a flight from New York to Paris at 9:00 on Saturday evening, we can conclude from this that there is no such flight; if I do not know that I have a brother, it is reasonable to conclude from this that I have no brother. But there are other situations in which closed-world reasoning is much less appropriate: to take an extreme example, if I do not happen to know that Secretary of State Clinton is wearing a blue suit today, it would be unreasonable to conclude from this that she is in fact, not wearing a blue suit.

Rather than assuming that closed-world reasoning applies uniformly to legal factors or that it uniformly fails Ashley and Vincent Aleven suppose, more sensibly, that this form of reasoning applies for some factors but fails for others. ${ }^{27}$ In the domain of trade secrets law, for example, they argue that closed-world reasoning can be applied to the factor representing the existence of an explicit confidentiality agreement between plaintiff and defendant: lacking positive information indicating such an agreement, that is, the court can legitimately conclude that there is none. But they deny that this form of reasoning can be applied to the factor representing the existence simply of a confidential relationship between plaintiff and defendant: even lacking explicit information indicating such a relationship, the court cannot conclude that no such relationship exists-the presumption of confidentiality is too strong.

If this analysis is correct, then the presence of a negative factor cannot be defined as nothing but the absence of the corresponding positive factor. A fact situation cannot therefore be represented simply as a list of positive factors, with all negative factors calculated implicitly through closed-world reasoning. Instead, both positive and negative factors must, at times, be listed as basic components of the fact situation; fact situations must be allowed to contain both factors and their negations explicitly. And in that case, many of our fundamental ideas, including the crucial notions of a preference ordering on considerations and a strength ordering on cases, which currently apply to fact situations containing only positive factors, will have to be generalized to apply to these richer fact situations as well.

The remaining generalizations I mention involve weakening two of the simplifying assumptions underlying the present account.

First, as noted above, this account relies on the idea that every legal factor favors one side or the other, either the plaintiff or the defendant. This is, in many ways, a plausible assumption, especially for relatively mature areas of the law. It is hard to think of a factor that, while legally relevant, does not favor one side or another; and certainly the analysis mentioned above of actual legal cases by Ashley and his colleagues involves only factors favoring

27. See Aleven, supra note 8, at 239-247 for a list of various legal factors to which closed-world reasoning does or does not apply. 
some particular side. Still, there are arguments within moral philosophy suggesting that the polarity of certain factors the side they favor, might vary depending on the context in which they appear-that a particular factor might favor one side when taken together with one group of factors, and a different side when taken together with a different group. ${ }^{28}$ The basic idea can be illustrated with an example entirely outside the moral or legal domain - a situation in which an individual is trying to decided whether conditions are favorable for an afternoon run. It is easy to imagine that both extreme heat and rain might count as unfavorable factors tending to rule out a run but that a combination of heat and rain together is acceptable, perhaps even refreshing. On one natural interpretation, what this example suggests is that neither heat nor rain itself has any independent polarity with respect to the classification of a situation as favorable for running, since each of these features tends to make the situation less favorable in one context, when present alone, but more favorable in another, when both features are present together.

The issues surrounding examples like this are complicated, and of course other interpretations are possible as well; perhaps what this particular example shows is that the basic factors involved in the domain are actually heat-without-rain and rain-without-heat, both of which would have negative polarity, and heat-and-rain-together, which would have positive polarity. Nevertheless, such examples, as well as other considerations from the literature, give life to the possibility that certain factors might have variable polarity, favoring different sides of an issue depending on the context in which they occur. If this turns out to be true, then several of our current ideas-including, once again, the crucial notions of a preference ordering on considerations and a strength ordering on cases, which currently apply to fact situations containing only positive factors-will have to be generalized to allow for this possibility. ${ }^{29}$

And second, as shown above, the present account simplifies by assuming that precedential reasoning involves only a single step proceeding from the factors present in a case directly to a decision in favor of the plaintiff or the defendant, instead of moving through a series of intermediate legal concepts. In fact, this hardheaded perspective still has some adherents. However it is often argued that an accurate account of legal reasoning must accord at least some meaning to the intermediate steps through which the outcome in a precedent case is determined.

28. See Jonathan Dancy, Moral Reasons (1993); and Jonathan Dancy, Ethics without PrinCIPLES (2004) for arguments in favor of this position, and BRAD HOOKER \& MARGARET LITTLE, Moral Particularism (2000), for a collection of essays on the topic; my own views on Dancy's argument are developed in Horty supra note 10.

29. Henry Prakken \& Giovanni Sartor, Modelling Reasoning with Precedents in a Formal Dialogue Game, 6 ARTificial InTELLIGENCE \& L. 231-287 (1998), develop a model of precedential reasoning with polarity-free factors; the idea is also explored in John Horty, Precedent, Deontic Logic, and Inheritance, in ProceEdings of THE SEVEnth InTERnational Conference on ARTificial INTELLIGENCE AND LAW (ICAIL-99), 63-72 (1999). 
In order to accommodate this broader point of view, the current framework would have to be generalized considerably. Rather than focusing only on structures of the form $\langle X, r, s\rangle$ in which $X$ is a set of factors, $r$ is a rule, and $s$ is an immediate decision for the plaintiff or defendant - that is, either $\pi$ or $\delta$-we would have to allow now, that $s$ may simply be another, higherlevel factor. Such a precedent constituent could be thought of as representing, on the basis of a particular set of factors, a decision that some further factor should also be included in a description of the fact situation; and taking the outcomes $\pi$ and $\delta$ as special factors, the class of precedent constituents could then be seen to generalize our previous cases. In this broader framework, an entire precedent case could then be represented as a linked set of precedent constituents, beginning with a characterization of the initial fact situation as a set of base-level factors, proceeding through a series of higherlevel legal concepts, and eventually arriving at a decision, based in part on these higher-level concepts, for the plaintiff or defendant. Incorporating this more detailed picture of legal reasoning into the present framework would be a complicated project, of course, but some ideas along these lines have already been explored in the literature on artificial intelligence and law. ${ }^{30}$

\section{A. CASES AND FACT SITUATIONS}

1. $c_{1}=\left\langle X_{1}, r_{1}, s_{1}\right\rangle$, where $X_{1}=\left\{f_{1}^{\pi}, f_{2}^{\pi}, f_{3}^{\pi}, f_{1}^{\delta}, f_{2}^{\delta}, f_{3}^{\delta}, f_{4}^{\delta}\right\}$, where $r_{1}$ is $\left\{f_{1}^{\pi}, f_{2}^{\pi}\right\} \rightarrow \pi$, and where $s_{1}$ is $\pi$.

2. $c_{2}=\left\langle X_{2}, r_{2}, s_{2}\right\rangle$, where $X_{2}=\left\{f_{1}^{\pi}, f_{2}^{\pi}, f_{4}^{\pi}, f_{5}^{\delta}, f_{6}^{\delta}\right\}$, where $r_{2}$ is $\left\{f_{5}^{\delta}\right\} \rightarrow \delta$, and where $s_{2}$ is $\delta$.

3. $c_{3}=\left\langle X_{3}, r_{3}, s_{3}\right\rangle$, where $X_{3}=\left\{f_{1}^{\pi}, f_{2}^{\pi}, f_{5}^{\pi}, f_{5}^{\delta}, f_{7}^{\delta}\right\}$, where $r_{3}\left(=r_{2}\right)$ is $\left\{f_{5}^{\delta}\right\} \rightarrow \delta$, and where $s_{3}$ is $\delta$.

4. $c_{4}=\left\langle X_{4}, r_{4}, s_{4}\right\rangle$, where $X_{4}=X_{3}=\left\{f_{1}^{\pi}, f_{2}^{\pi}, f_{5}^{\pi}, f_{5}^{\delta}, f_{7}^{\delta}\right\}$, where $r_{4}$ is $\left\{f_{5}^{\pi}\right\} \rightarrow \pi$, and where $s_{4}$ is $\pi$.

5. $c_{5}=\left\langle X_{5}, r_{5}, s_{5}\right\rangle$, where $X_{5}=X_{4}=X_{3}=\left\{f_{1}^{\pi}, f_{2}^{\pi}, f_{5}^{\pi}, f_{5}^{\delta}, f_{7}^{\delta}\right\}$, where $r_{5}$ is $\left\{f_{1}^{\pi}\right\} \rightarrow \pi$, and where $s_{5}$ is $\pi$.

6. $c_{6}=\left\langle X_{6}, r_{6}, s_{6}\right\rangle$, where $X_{6}=\left\{f_{1}^{\pi}, f_{2}^{\delta}\right\}$, where $r_{6}$ is $\left\{f_{2}^{\delta}\right\} \rightarrow \delta$, and where $s_{6}$ is $\delta$.

7. $c_{7}=\left\langle X_{7}, r_{7}, s_{7}\right\rangle$, where $X_{7}=\left\{f_{1}^{\pi}, f_{1}^{\delta}\right\}$, where $r_{7}$ is $\left\{f_{1}^{\pi}\right\} \rightarrow \pi$, and where $s_{7}$ is $\pi$.

8. $c_{8}=\left\langle X_{8}, r_{8}, s_{8}\right\rangle$, where $X_{8}=\left\{f_{2}^{\pi}, f_{1}^{\delta}\right\}$, where $r_{8}$ is $\left\{f_{1}^{\delta}\right\} \rightarrow \delta$, and where $s_{8}$ is $\delta$.

9. $X_{9}=\left\{f_{2}^{\pi}, f_{2}^{\delta}\right\}$.

10. $c_{10}=\left\langle X_{10}, r_{10}, s_{10}\right\rangle$, where $X_{10}=X_{5}=X_{4}=X_{3}=\left\{f_{1}^{\pi}, f_{2}^{\pi}, f_{5}^{\pi}, f_{5}^{\delta}, f_{7}^{\delta}\right\}$, where $r_{10}$ is $\left\{f_{7}^{\delta}\right\} \rightarrow \delta$, and where $s_{10}$ is $\delta$.

11. $c_{11}=\left\langle X_{11}, r_{11}, s_{11}\right\rangle$, where $X_{11}=\left\{f_{5}^{\pi}, f_{6}^{\pi}, f_{5}^{\delta}, f_{7}^{\delta}\right\}$, where $r_{11}\left(=r_{2}\right)$ is $\left\{f_{5}^{\delta}\right\} \rightarrow \delta$, and where $s_{11}$ is $\delta$.

12. $X_{12}=\left\{f_{1}^{\pi}, f_{1}^{\delta}, f_{2}^{\delta}\right\}$.

13. $X_{13}=\left\{f_{1}^{\pi}, f_{2}^{\pi}, f_{1}^{\delta}\right\}$.

30. See, e.g., L. Karl Branting, Reasoning with Portions of Precedents, in ProceEdings OF THE THIRD INTERNATIONAL CONFERENCE ON ARTIFICIAL INTELLIGENCE AND LAW (ICAIL-91), 145-154 (1991); L. Karl Branting, A Computational Model of Ratio Decidendi, 2 ArTifiCIAL INTELLIGENCE \& L. 1-31 (1994); Prakken \& Sartor, supra note 29; and Horty, supra note 29. 
14. $X_{14}=\left\{f_{1}^{\pi}, f_{2}^{\pi}, f_{3}^{\pi}, f_{1}^{\delta}\right\}$.

15. $X_{15}=\left\{f_{1}^{\pi}, f_{2}^{\pi}, f_{1}^{\delta}\right\}$.

\section{B. OBSERVATIONS AND PROOFS}

Observation 1. Let $\Gamma$ be a case base containing two precedent cases of the form $\langle X, r, s\rangle$ and $\left\langle X, r^{\prime}, \bar{s}\right\rangle$. Then $\Gamma$ is inconsistent.

Proof Suppose the case base $\Gamma$ contains the cases $c=\langle X, r, s\rangle$ and $c^{\prime}=$ $\left\langle X, r^{\prime}, \bar{s}\right\rangle$. By our coherence constraints on rules and cases-particularly the requirements that the premise of a rule can contain only factors supporting its conclusion along with the requirement that the rule of a case must be applicable to its fact situation-we have (1) Premise $(r) \subseteq X^{s}$, and (2) Premise $\left(r^{\prime}\right) \subseteq X^{\bar{s}}$, and obviously (3) Premise $(r) \subseteq \operatorname{Premise}(r)$, and (4) Premise $\left(r^{\prime}\right) \subseteq \operatorname{Premise}\left(r^{\prime}\right)$. From (2) and (3), we have Premise $\left(r^{\prime}\right)<_{c}$ Premise $(r)$ by Definition 2, and likewise Premise $(r)<_{c^{\prime}}$ Premise $\left(r^{\prime}\right)$ by $(1)$ and (4). We therefore have both Premise $\left(r^{\prime}\right)<_{\Gamma} \operatorname{Premise}(r)$ and Premise $(r)<_{\Gamma}$ Premise $\left(r^{\prime}\right)$ by Definition 3, and so Definition 7 tells us that $\Gamma$ is inconsistent.

Observation 2. Let $\Gamma$ be a consistent case base, and suppose $X$ is a fact situation in which none of the rules from $\operatorname{Rule}(\Gamma)$ are applicable. Then $\Gamma \cup$ $\{\langle X, r, s\rangle\}$ is also consistent, where $r$ is any newly formulated rule applicable in $X$ and supporting $s$ as an outcome.

Proof Assume that $\Gamma$ is consistent and that $X$ is a fact situation in which none of the rules from Rule $(\Gamma)$ are applicable. Now suppose for contradiction that $\Gamma \cup\{c\}$ is not consistent where $c=\langle X, r, s\rangle$ with $r$ a newly formulated rule supporting $s$. Since $\Gamma$ is consistent but $\Gamma \cup\{c\}$ is not, the preference relation derived from $c$ must conflict with the preference relation derived from some other case already belonging to $\Gamma$ - that is, there must be reasons $A$ and $B$ such that (1) $A<_{c} B$, and (2) $B<_{c^{\prime}} A$, where $c^{\prime}=\left\langle Y, r^{\prime}, \bar{s}\right\rangle$ is a case from $\Gamma$. From (1) we have (3) $A \subseteq X^{\bar{s}}$, and (4) Premise $(r) \subseteq B$ by Definition 2, and likewise from (2) we have (5) $B \subseteq Y^{s}$, and (6) Premise $\left(r^{\prime}\right) \subseteq A$. From (3) and (6), together with the fact that $X^{\bar{s}} \subseteq X$, we have Premise $\left(r^{\prime}\right) \subseteq X$, and of course $r^{\prime}$ belongs to $\operatorname{Rule}(\Gamma)$, so that some rule from $\operatorname{Rule}(\Gamma)$ is applicable to $X$, contrary to assumption.

Observation 3. Let $\Gamma$ be a consistent case base with $R u l e(\Gamma)$ the derived set of rules, and suppose $X$ is a fact situation in which some rule $r$ from $\operatorname{Rule}(\Gamma)$, supporting the outcome $s$, is binding. Then the case base $\Gamma \cup\{\langle X, r, s\rangle\}$ is also consistent.

Proof Assume that $\Gamma$ is consistent with $X$ is a fact situation in which the rule $r$ from Rule $(\Gamma)$, supporting the outcome $s$, is binding. Now suppose for contradiction that $\Gamma \cup\{c\}$ is not consistent where $c=\langle X, r, s\rangle$. Since $\Gamma$ 
is consistent but $\Gamma \cup\{c\}$ is not, the preference relation derived from $c$ must conflict with the preference relation derived from some other case already belonging to $\Gamma$ - that is, there must be reasons $A$ and $B$ such that (1) $A<_{c} B$, and (2) $B<_{c^{\prime}} A$, where $c^{\prime}=\left\langle Y, r^{\prime}, \bar{s}\right\rangle$ is a case from $\Gamma$. From (1) we have (3) $A \subseteq X^{\bar{s}}$, and (4) Premise ( $\left.r\right) \subseteq B$ by Definition 2, and likewise from (2) we have (5) $B \subseteq Y^{s}$, and (6) Premise $\left(r^{\prime}\right) \subseteq A$. From (3) and (6), together with the fact that $X^{\bar{s}} \subseteq X$, we have Premise $\left(r^{\prime}\right) \subseteq X$, so that the rule $r^{\prime}$ is applicable in the situation $X$. From (4) and (5) we have (6) Premise $(r) \subseteq$ $Y^{s}$, and obviously (7) Premise $\left(r^{\prime}\right) \subseteq$ Premise $\left(r^{\prime}\right)$. By Definition 2, then, (6) and (7) tell us that Premise $(r)<_{c^{\prime}}$ Premise $\left(r^{\prime}\right)$, from which it follows that Premise $(r)<_{\Gamma}$ Premise $\left(r^{\prime}\right)$. Since the rule $r^{\prime}$ from Rule $(\Gamma)$, which supports a different conclusion, is both applicable in $X$ and stronger than $r$, it follows from Definition 5 that $r$ is trumped. By Definition 6, therefore, the rule $r$ is not binding, contrary to assumption.

Observation 4. Let $\Gamma$ be a case base containing two precedent cases of the form $\langle X, r, s\rangle$ and $\left\langle Y, r^{\prime}, \bar{s}\right\rangle$ where $X \leq^{s} Y$. Then $\Gamma$ is inconsistent.

Proof Suppose the case base $\Gamma$ contains the cases $c=\langle X, r, s\rangle$ and $c^{\prime}=$ $\left\langle Y, r^{\prime}, \bar{s}\right\rangle$ where $X \leq^{s} Y$. By our coherence constraints on rules and casesparticularly the requirements that the premise of a rule can contain only factors supporting its conclusion along with the requirement that the rule of a case must be applicable to its fact situation-we have (1) Premise $(r) \subseteq$ $X^{s}$, and (2) Premise $\left(r^{\prime}\right) \subseteq Y^{\bar{s}}$, and obviously (3) $X^{\bar{s}} \subseteq X^{\bar{s}}$ and (4) $Y^{s} \subseteq Y^{s}$. Because $X \leq^{s} Y$, it follows from Definition 9 that $X^{s} \subseteq Y^{s}$, and so from (1) that (5) Premise $(r) \subseteq Y^{s}$. From (3) and (5) we therefore have (6) $X^{\bar{s}}<_{c} Y^{s}$ by Definition 2. Because $X \leq^{s} Y$, again, we also have $Y \leq^{\bar{s}} X$ by the duality property of the $\leq^{s}$ relation. It therefore follows from Definition 9 that $Y^{\bar{s}} \subseteq X^{\bar{s}}$, and so from (2) that (7) Premise $\left(r^{\prime}\right) \subseteq X^{\bar{s}}$. From (4) and (7) we have (8) $Y^{s}<_{c^{\prime}} X^{\bar{s}}$ by Definition 2. From (6) and (8) we therefore have both $X^{\bar{s}}<_{\Gamma} Y^{s}$ and $Y^{s}<_{\Gamma} X^{\bar{s}}$ by Definition 3, and so Definition 7 tells us that $\Gamma$ is inconsistent.

Observation 5. Let $\Gamma$ be a consistent case base and $X$ a new fact situation confronting the court, and suppose a fortiori constraint requires the court to reach a decision for the side $s$ in the situation $X$. Then precedential constraint also requires the court to reach a decision for the side $s$.

Proof Suppose $\Gamma$ is a consistent case base with $X$ a fact situation in which the court is required by a fortiori constraint to reach a decision for the side $s$. By Definition 10, then, there must be some case of the form $\langle Y, r, s\rangle$ in $\Gamma$ for which $Y \leq^{s} X$. In order to show that precedential constraint also requires a decision for $s$, we must show, by Definition 8 , that the result of augmenting $\Gamma$ with a contrary decision-that is, with a case of the form $\left\langle X, r^{\prime}, \bar{s}\right\rangle$ where $r^{\prime}$ is some rule supporting the outcome $\bar{s}$-would be inconsistent. But this follows at once from Observation 4. 
Observation 6. Consider only cases $\langle X, r, s\rangle$ in which the rule $r$ has the form $X^{s} \rightarrow s$. Let $\Gamma$ be a consistent set of such cases, and suppose that $Y$ is a new fact situation confronting the court. Then a fortiori constraint requires the court to reach a decision for some particular side in this situation if and only if precedential constraint requires a decision for the same side.

Proof Observation 5 shows that following a fortiori constraint implies following precedential constraint in general, and so it remains only to show that following precedential constraint implies following a fortiori constraint under the assumption that any rule $r$ in a case of the form $\langle X, r, s\rangle$ itself has the form $X^{s} \rightarrow s$. Under this assumption, then, suppose that $\Gamma$ is a consistent case base against the background of which precedential constraint requires a decision for $s$ in the new fact situation $Y$. What this means, according to Definition 8 , is that the result of augmenting $\Gamma$ with a contrary decision of the form $c=\langle Y, r, \bar{s}\rangle$ would then be inconsistent-that is, there must be reasons $A$ and $B$ such that (1) $A<_{c} B$, and (2) $B<_{c^{\prime}} A$, where $c^{\prime}=\left\langle X, r^{\prime}, s\right\rangle$ is a case already belonging to $\Gamma$. From (1) we have by Definition 2 both (3) $A \subseteq Y^{s}$, and also (4) $Y^{\bar{s}} \subseteq B$, since Premise ( $r$ ) has the form $Y^{\bar{s}}$ by our assumption; and likewise from (2) we have both (5) $B \subseteq X^{\bar{s}}$, and also (6) $X^{s} \subseteq A$, since Premise $\left(r^{\prime}\right)$ has the form $X^{s}$. Evidently, (3) and (6) tell us that $X^{s} \subseteq Y^{s}$, and (4) and (5) that $Y^{\bar{s}} \subseteq X^{\bar{s}}$. We therefore have $X \leq^{s} Y$ by Definition 9 , and so, since $c^{\prime}$ belongs to $\Gamma$, it follows from Definition 10 that a fortiori constraint requires a decision for $s$ in the case of $Y$.

\section{REFERENCES}

Aleven, Vincent. (1997) “Teaching Case-Based Argumentation through a Model and Examples.” Ph.D. thesis, Intelligent Systems Program, University of Pittsburgh.

Aleven, Vincent, and Kevin Ashley. (1997) "Evaluating a Learning Environment for Case-Based Argumentation Skills.” In Proceedings of the Sixth International Conference on Artificial Intelligence and Law (ICAIL-97), 170-179 (New York: Association for Computing Machinery Press).

Alexander, Larry. (1989) “Constrained by Precedent.” Southern California Law Review, 63: 1-64.

- (1996) "Precedent." In Dennis Patterson, ed., A Companion to Philosophy of Law and Legal Theory, 503-513 (Blackwell).

Alexander, Larry, and Emily Sherwin. (2001) The Rule of Rules: Morality, Rules, and the Dilemmas of Law (Duke University Press).

—. (2007) "Judges as Rule Makers." In Douglas Eldin, ed., Common Law Theory, 27-50 (Cambridge University Press).

Ashley, Kevin. (1989) "Toward a Computational Theory of Arguing with Precedents: Accommodating Multiple Interpretations of Cases." In Proceedings of the Second International Conference on Artificial Intelligence and Law (ICAIL-89), 93-110 (Association for Computing Machinery Press).

Press). 
Branting, L. Karl. (1991) "Reasoning with Portions of Precedents." In Proceedings of the Third International Conference on Artificial Intelligence and Law (ICAIL-91), 145-154 (Association for Computing Machinery Press).

- (1994) "A Computational Model of Ratio Decidendi." Artificial Intelligence and Law 2: 1-31.

Cross, Rupert. (1968) Precedent in English Law, 2nd ed. (Oxford University Press).

Dancy, Jonathan. (1993) Moral Reasons (Basil Blackwell Publisher).

- (2004) Ethics without Principles (Oxford University Press).

Goodhart, Arthur. (1930) "Determining the Ratio Decidendi of a Case." Yale Law Journal 40: 161-183.

Hooker, Brad, and Margaret Little. (2000) Moral Particularism (Oxford University Press).

Horty, John. (1999) "Precedent, Deontic Logic, and Inheritance." In Proceedings of the Seventh International Conference on Artificial Intelligence and Law (ICAIL-99), 63-72 (Association for Computing Machinery Press).

_. (2004) “The Result Model of Precedent.” Legal Theory 10: 19-31.

- (2007) "Reasons as Defaults." Philosophers' Imprint 7 available at http:// pholosophersimprint.org/007003/.

Kornhauser, Lewis, and Lawrence Sager. (1986) "Unpacking the Court." Yale Law Journal, 96: 82-117.

Lamond, Grant. (2005) "Do Precedents Create Rules? Legal Theory, 11: 1-26.

Levi, Edward. (1949) An Introduction to Legal Reasoning (University of Chicago Press).

Prakken, Henry, and Giovanni Sartor. (1998) "Modelling Reasoning with Precedents in a Formal Dialogue Game." Artificial Intelligence and Law 6: 231-287.

Raz, Joseph. (2002) Practical Reasoning and Norms, 2nd ed. (Oxford University Press).

- (1979) The Authority of Law (Oxford University Press).

Rissland, Edwina. (1990) “Artificial Intelligence and Law: Stepping Stones to a Model of Legal Reasoning.” Yale Law Journal 99: 1957-1981.

Schauer, Frederick. (1989) "Is the Common Law Law?" California Law Review 77: $455-471$.

. (1991) Playing by the Rules: A Philosophical Examination of Rule-Based DecisionMaking in Law and Life (Oxford University Press).

Simpson, A.W.B. (1961) "The Ratio Decidendi of a Case and the Doctrine of Binding Precedent." In A.G. Guest, ed., Oxford Essays in Jurisprudence, 148-175 (Oxford University Press). 